Cathleen Martyniak

UF Dissertation Project

Preservation Department

University of Florida Libraries

P.O. Box 117008

Gainesville, FL 32611-7008

Dear Ms. Martyniak:

I am pleased to learn of the UF Dissertation Project, and to make my "aged" dissertation available for researchers. However, there are two errors that must be corrected to successfully raise larvae of the lesser cornstalk borer using the methods listed. On page 13, the first sentence of the first full paragraph should read:

Each cage with pupae was numbered and put in a culture room at $30+1$ degrees centigrade, $30 \%$ relative humidity, and daily photoperiod of $13 \mathrm{hrs} \mathrm{light.}$

I hereby authorize you or whomever you appoint to make these changes.

Thank you for your assistance. I wish you the best of success with this new project.

Sincerely,

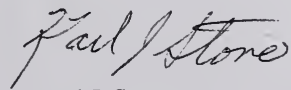

Karl J. Stone 


\title{
REPRODUCTIVE BIOLOGY OF THE LESSER CORNSTALK BORER, ELASMOPALPUS LIGNOSELLUS (ZELLER) (LEPIDOPTERA: PHYCITIDAE)
}

By

KARL JOHNSON STONE

\begin{abstract}
A DISSERTATION PRESENTED TO THE GRADUATE COUNCIL OF THE UNTVERSITY OF FLORIDA

IN PARTLAL FULFILLMENT OF THE REQUIREMENTS FOR THE DEGREE OF DOCTOR OF PHILOSOPHY
\end{abstract}

UNIVERSITY OF FLORIDA

1968 


\section{ACKNOWLEDGEMENTS}

I greatly appreciate the advice and criticism offered by Dr. T. J. Waiker, chairman of my supervisory committee, during the research and preparation of the dissertation.

Appreciation is gratefully extended to Dr. L. A. Hetrick and Dr. J. T. Creighton, Depariment of Entomology; Dr. D. B. Ward, Departmient of Botany; Dr. G. C. LaBrecque, United States Department of Agriculture, Entomology Research Division; and Dr. H. K. Wallace, Chairman of the Department of Zoology, who served as members of the supervisory commitiee.

Appreciation is extended to Dr. W. G. Eden, Chairman of the Department of Entomology for providing assistants who helped maintain the insect colony.

Special thanks is expressed to Mr. J. Beckner, Department of Bolany for his assistance in botanical nomenclature, and to Mr. P. U. Roos for assistance in translating French and German material.

Sincere gratitude is extended to my wife for her generous assistance, patience, and constant encouragement involving long hours and many sacrifices. 
TABLE OF CONTENTS

Page

ACKNOWLEDGEMENTS.

LIST OF TABLES

LIST OF FIGURES.

INTRODUCTION .

REVIEW OF LITERATURE

General References. . . . . . . . . . . . 3

Host Plants . . . . . . . . . . . . . . 3

MATERIALS AND METHODS • . . . . . . . . . . . 12

Rearing Techniques . . . . . . . . . . 12

General Methods . . . . . . . . . . . 12

Aberrant Pupae. . . . . . . . . . . . . 19

Other Materials and Methods . . . . . . . . . 21

MORPHOLOGICAL STUDIES . . . . . . . . . . . 22

Morphology of the Reproductive System . . . . . . . 22

Materials and Methods. . . . . . . . . . . 22

Results and Discussion . . . . . . . . . . . 22

Male . . . . . . . . . . . . . 22

Female. . . . . . . . . . . . 26

The Spermatophore . . . . . . . . . . . . 29

Materials and Methods. . . . . . . . . . 31

Results and Discussion . . . . . . . . . . 31

Primary Simplex and Spermatophore Color . . . . . . . 33

Materials and Methads. . . . . . . . . . 33

Results and Discussion . . . . . . . . . . 34

Egg Development and Position Relative to Age . . . . . . 35

Materials and Methods. . . . . . . . . . . 37

Results and Discussion . . . . . . . . . . 37 
Morphology of the Tympanic Organ

Materials and Methods. . . . . . . . . . . 40

Results and Discussion. . . . . . . . . . . . . 40

BEHAVIORAL STUDIES . . . . . . . . . . . . . . 45

Mating Cage Conditions . . . . . . . . . . . . 45

Materials and Methods. . . . . . . . . . . 45

Results and Discussion. . . . . . . . . . . 46

Mating Behavior . . . . . . . . . . . . . 48

Materials and Methods. . . . . . . . . . 49

Results and Discussion. . . . . . . . . . . 50

Influence of Additional Females on Male Mating Frequency . . . 54

Materials and Methods. . . . . . . . . . 54

Results and Discussion . . . . . . . . . 55

Influence of Age on Mating . . . . . . . . . . . . . 55

Materials and Methods. . . . . . . . . . 56

Results and Discussion . . . . . . . . . . 56

Influence of Male Antennectomy on Mating . . . . . . . 56

Materials and Methods. . . . . . . . . . . 58

Results and Discussion . . . . . . . . . . . . . 58

Longevity of Virgin and Mated Moths, Spermatophore Passage and

Acceptance, and Fecundity . . . . . . . . . 58

Materials and Methods. . . . . . . . . . 59

Results and Discussion. . . . . . . . . . 60

Time of Oviposition . . . . . . . . . . . . 76

Materials and Methods. . . . . . . . . . 77

Results and Discussion . . . . . . . . . . 77

Response of Adults to Sound . . . . . . . . . . . 77

Materials and Methods. . . . . . . . . . . 80

Results and Discussion... . . . . . . . . 82

SUMMARY . . . . . . . . . . . . . . . 85

LITERATURE CITED . . . . . . . . . . . . . . . 88

BIOGRAPHICAL SKETCH. . . . . . . . . . . . 95 


\section{LIST OF TABLES}

Table

1 Reported host plants of the lesser cornstalk borer.. . . . . . 6

2 Composition of medium for lesser cornstalk borer larvae. . . . . 16

3 Color fluid in the 1st secretory area of the primary simplex of 3day-old mated anó unmated lesser cornstalk borer males at different periods of the day following mating the previous night. . . 36

$4 \quad$ Cage conditions and spermatophores passed by 2-cay-old fed and unfed lesser cornstalk borer adults, tested for 4 nights in 40-dr vials, 1 pair per vial, 22 replicates per test. . . . . . . . 47

5 Longevity of lesser cornstalk borer adults. . . . . . . 61

6 Spermatophore passage and acceptance during the lifetime of various Lepidoptera. . . . . . . . . . . . . . 63

7 Fecundity of the lesser cornstalk borer. . . . . . . . 69

8 Lesser corristalk borer females showing 2 or more variations from basic population oviposition patterns. . . . . . . . 73 


\section{LIST OF FIGURES}

Figure

1 Cages used in rearing technique. A. Mating-oviposition cage.

B. Rearing cage. . . . . . . . . . . . 14

2 Veniral view of terminal pupal abdoinina! segments of the lesser cornstalk borer. . . . . . . . . . . 18

3 Reproductive system of the male lesser cornstalk borer. . . . 25

4 Reproductive system of the female lesser cornstalk borer. . . . 28

5 Spermatophore of the lesser cornstalk borer. . . . . . 32

6 Egg development and position in the reproductive tract of lesser cornstalk borer virgin females relative to age. . . . . . 38

7 External anterior view of the first abdominal segment of the lesser cornstalk borer moth illustrating the tympanic organs on the excised abdomen. . . . . . . . . . . . . . .

8 Internal lateral view of the right tympanic organ of the lesser cornstalk moth with the lateral wall of the tympanic sac removed.

9 Percent mating of 1-6-day-old lesser cornstalk borer adults caged for 1 day . . . . . . . . . . . . . 57

10 Mated lesser cornstalk borer male longevity and spermatophores passed.

11 Mated lesser cornstalk borer female longevity, oviposition period, fecundity, and spermatophores accepted.. . . . . . 65

12 Toral number of spermatophores passed per day by 25 lesser cornstalk borer males, number of males after day 14 as indicated. .

13 Average numbers of eggs laid per day by 25 lesser cornstalk borer mated females, number of females after day 12 as indicated. 
Figure

14 Diurnal and nocturnal response of lesser cornstalk borer adults to various amplitudes and frequencies. 


\section{INTRODUCTION}

The lesser cornstalk 'oorer, Elasmopalpus lignosellus (Zeller), is an important pest of crops in Florida, causing considerable damage to corn, soybeans, peanuts, sugar cane, field peas, southern peas, and rye. The moth is widely distributed throughout the tropical and temperate regions of the New World, including the southern half of the United Siates from California to the Carolinas, north on the East Coast to Massachusetts, and south thru Central America and South America to Argentina, Chile, and Peru (Heinrich, 1956).

Damage to crops in Florida occurs primarily in areas with muck or sandy soils (Strayer, J. R. ${ }^{1}$ 1968. Personal communication.). Luginbill and Ainslie (1917) and Lyle (1927) found that damage usually seems greater on thin sandy soils in South Carolina, Florida, and Mississippi. King et al. (1961) in Texas reported damage is especially severe during drought periods. Leuck (1966) in Georgia reported larvae damage seedlings during drought and when late plantings are followed by hot a'ry periods. Wide-spread infestations have led to several insecticidal investigations.

However, little is known about the moth's reproductive biology. Basic research in this area was facilitated by rearing the insect in the laboratory and examining the reproductive morphology with respect to structure ond changes occurring when moths

1 Assistant Extension Entomologist, Institute of Food and Agricultural Sciences, University of Florida. 
mated or aged. In addition the morphology of the tympanic organ is discussed.

Behavioral studies included mating behavior and various factors which influenced this activity: cage conditions, additional females on male mating frequency, age, and male antennectomy. The longevity of virgin and mated moths, spermatophore passage patterns, and fecundity were studied, as well as time of oviposition. Lastly, the response of adults to sound was observed.

The above information may facilitate studies on the effects of chemosterilants, antimetabolites, and predator and parasite relationships. 


\section{REVIEW OF LITERATURE}

\section{General References}

The literature contains considerable research on insecticidal control of the lesser cornstalk borer, but little is known about its biology. Below are the papers that deal with reproductive biology and rearing methods.

Luginbill and Ainslie (1917), using moths from South Carolina and Florida, discussed rearing methods and mating cage conditions, as well as longevity, fecundity, and time of mating. Sanchez (1960), Dupree (1965), Leuck (1966), and Calvo (1966) discussed similar factors with moths from Texas, Georgia, and Florida.

\section{Host Plants}

The lesser cornstalk borer attacks many weeds and crops, especially legumes and grasses, throughout the southern half of the United States (King et al., 1961).

Table 1 lists 62 host plants of the lesser cornstalk borer. The following 14 families are represented: Chencpodiaceae, Corivolvulaceae, Cruciferae, Cucurbitaceae, Cyperaceae, Gramineae, Iridaceae, Leguminosae, Linaceae, Malvaceae, Pinaceae, Rosaceae, Rutaceae, and Solanaceae. Confusion in the taxonomy of cultivated plants and commori names complicated compilation of the list, and in some cases, the same host is listed under different common names to indicate common usage in different parts of the country. In such cases, e.g. black-eyed beans = black-eyed 
peas, the host is counted only once in the total count of hosts. Where varietal names are available, each host is counted once. Scientific names were obtained from standard references (Bailey, 1949; Fernald, 1950; Hitchcock, 1951) and Hill's (1937) paper on cultivated sorghums.

Most authors consider the pest a subterranean feeder, but some reports suggest feeding on the aerial parts of plants. Similar feeding behavior of other species may have misled workers and confused host records. For instance, the phycitid moth, Ufa rubedinella (Zeller) (=Elasmopalpus rubedinellus (Zeller)), redescribed by Heinrich (1956) was reported feeding on leaves and fruits of lima beans and black-eyed peas in Florida (unpublished records, Florida Department of Agriculture, Division of Plant Industry, 19.44-1945). The larva webs debris in a manner similar to the lesser cornstalk borer, but the insect has nat been reported in the DPI files since 1945. Unidentified pyralid larvae were reported on peach seedlings by Dekle (1965) with the characteristic sand-debris subterranean funnels of E. lignosellus; however, the tunnels also extended up the stems and over leaves. 


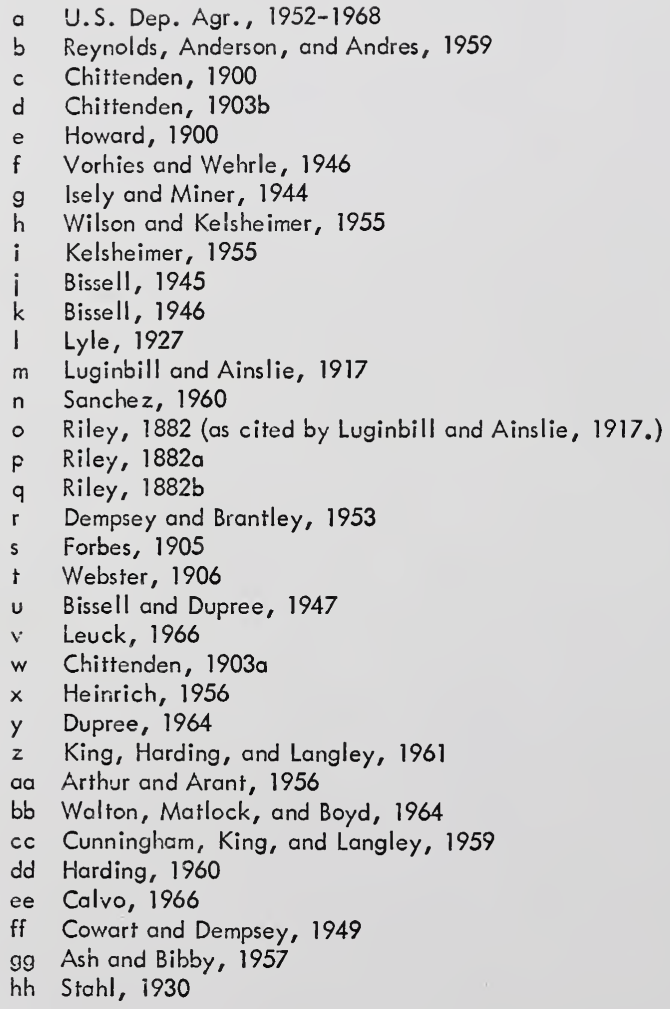


Table 1. -Reporied host plants of the lesser cornstalk borer

\begin{tabular}{|c|c|c|c|}
\hline Common Name & Scientific Name & Localities & References \\
\hline Alfalfa & Medicago sativa L. & $\begin{array}{l}\text { Ariz., Kans., } \\
\text { Tex. }\end{array}$ & a. \\
\hline Barley & Hordeum vulgare L. & Calif. & b. \\
\hline Beans & Phaseolus sp. & $\begin{array}{l}\text { Ala., Ariz., Ark., } \\
\text { Calif., Dela., } \\
\text { Fla., Ga., Md., } \\
\text { Miss., Mo., N.C., } \\
\text { Okla., S. C., } \\
\text { Tenn., Tex., Va. }\end{array}$ & $\begin{array}{l}a, b, c, d, e, \\
f, g, h, i, i, \\
k, l .\end{array}$ \\
\hline
\end{tabular}

field

Beans,

black-eyed

Beans,

bush

green

Beans,

lima

Beans,

mung

Beans,

pinto

pole

snap

string

Beets
N.C.

a.

Vigna sinensis Calif.

(L.) Endl.

Phaseolus vulgaris L. Tex.

var. humilis Alef.

Okla.

a.

$\frac{\text { Phaseolus limensis }}{\text { Macfad. }}$

Ala., Fla., Ga., Md., S.C., Va.

Phaseolus vulgaris L. Tex.

a.

Phaseolus vulgaris L. Ariz.

a.

Fla.

a.

Ala., Ark.,

Conn., Ga., Md.,

N.C., Okla.,

S.C., Tenn., Va.

Calif., Ga.

a.

Beta vulgaris $\mathrm{L} . \quad$ Ala.

a. 
Table 1 Continued

Common Name

Scientific Name

Localities

References

Cabbage

Brassica oleracea L. Fla.

a. var. capitata L.

Cane, Japanese

Saccharum officinarium Fla.

m.

sugar

L.

Fla., La., Miss.

$a, 1$.

Cantaloupe

Cucumis melo L. var. Calif., Tex.

$a, n$. cantalupensis Naud.

Chufa

Cyperus esculentus L. Fla.

m. var. sativus Boeckl.

Citrus

Citrus sp.

Fla.

a.

Clover, crimson

Trifolium incarnatum L. Ga. var. elatius Gibelli

\& Belli

Clover,

White Dutch

Trifolium repens L.

Fla.

a.

Cole

crops

Brassica sp.

Va.

a.

Corn

Zea mays L.

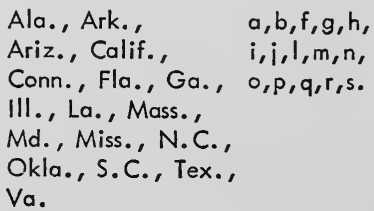

field

Fla., Ga., Tex.

a.

silage

Ga.

a.

Corn,

broom

Sorghum vulgare Pers. Okla.

a.

var. technicum

(Koern.) Fiori \&

Paoletti 
Corn,

kafir

Corn,

sweet

Cotton

Cowpeas

Flax

Foxtail

Gladiolus

Grass,

barnyard

Grass,

Bermuda

Grass,

Colorado

Grass,
crab

Grass,

Johnson

Grass,

nut

Grass, pangola

Sorghum vulgare Pers. Calif.

a.

var. caffrorum (Retz.)

Hubbard \& Rehder

Zea mays L. var.

rugosa Bonaf.

Ariz., Colif.,

a.

Fla.

Hibiscus gossypium L. Calif.

b.

Vigna sinensis

(L.) Endl.

Ala., Ariz., Ark., $a, d, f, g, h$, Fla., Ga., Miss., $i, j, k, 1, m$, N.C., Okla., $\quad t, u, v, w, x$. S.C., Tex., Va.

Linum usitatissimum $L$.

$x$.

Alopecurus pratensis L. Ark.

g.

Gladiolus sp.

Fla.

i.

Echinochloa crusgalli Ark.

g.

(L.) Beauv.

Cynodon dactylon

(L.) Pers.

Calif., Ga.

$b, y$.

Panicum texanum Buckl. Tex.

a.

Digitaria sanquinalis

(L.) Scop.

Sorghum halepense

(L.) Pers.

Cyperus esculentus L. Calif., Fla.

Digitaria decumbens

Stent. $b, i$.

Ark., Calif., Fla., Ga., Tex.

$a, b, g, h, n$, Md.

Ariz., Calif.,

Fla., Miss.,

Okla., Tex.

$a, b, h, n$.

$y$.

Fla.

a. 
Table I Continued

Common Name

Grass, Rhodes

Grass,

rye

Grass,

Sudan

Grass, water

Grass,

wire

Ground

burnut

Guar

Hegari

Locust, black

Lupine

Lupine, blue

Millet

Milo

maize

Oats

Oats, wild
Scientific Name

Localities

References

Chloris gayana Kunth Fla.

ee.

Lolium sp.

Fla.

a.

$\frac{\text { Sorghum sudanense }}{\text { (Piper) Stapf }}$

Tex.

a.

Cyperus sp.

Calif.

b.

Eleusine indica (L.)

Goertn.

Ga., s.C.

t.

Aegilops sp. ?

Tex.

z.

$\frac{\text { Cyamopsis psoralioides }}{\text { D.C. }}$ Tex.

a.

Sorghum vulgare Pers. Ariz., Tex.

$a, n$.

Robinia pseudoacacia L.

$x$.

Lupinus augustifolius L. Fla., Ga.

a. var. 'rancher'

Lupinus hirsutus L.

Fla.

a.

Panicum miliaceum L. La., S.C. a.

Sorghum subglabrescens Ariz., Tex.

$a, m$. (Steud.) A.F. Hill

Avena sativa L.

Ala., Calif., Miss., S.C., Tex.

$a, b, n$.

Avena barbata Brot. Calif.

b. 
Common Name

Papyrus

Peach

Peanuts

Peas

garden

winter

Peas,

Austrian

winter

field

Pisum sativum $L$.

var. arvense (L.) Poir.

Pisum sativum L.

$\frac{\text { Prunus persica }}{\text { (L.) Batsch }}$

Arachis hypogaea $\mathrm{L}$.

$\frac{\text { Vigna sinensis }}{\text { (L.) Endl. }}$

southern

southern table

Pimento

Pine,

loblolly

Potato, sweet

Pinus taeda L.
Localities

References

Calif.

a.

Fla.

a.

Ala., Ariz.,

$a, c, e, f, h$,

Calif., Fla.,

$i, l, n, y, z$,

Ga., Miss.,

N.C., Okla., $a a, b b, c c$,

S.C., Tex.

dd.

Ala., Ariz., $\quad a, b$.

Ark., Calif.,

Fla., Ga., N.C.,

Okla., S.C., Tex.

Ala.

a.

Tex.

a.

Tex.

a.

Ala., Calif., $a, n$.

Fla., Ga., Miss.,

Tex.

Ala., Ariz., $\quad a, n$. Calif., Ga., Tex.

Ala.

a.

Ala.

a.

Capsicum frutescens L. Dela., Fla., Ga. a,i,i,r,ff.

Va.

a.

Ipomoea batatas Lam. Calif., Fla., Ga. a. 
Table 1 Continued

Common Name

Rice

Rye

Sorghum

Sorghum,

grain

Sorghum,

Sudan

Soybeans

Stock,

garden

Strawberries

Tomatoes

Turnips

Vetch

Wheat
Scientific Name

Oryza sativa L.

Secale cereale $\mathrm{L}$.

$\frac{\text { Sorghum vulgare Pers. }}{\text { var. vulgare }}$

$\frac{\text { Sorghum vulgare Pers. }}{\text { var. vulgare }}$

Sorghum almum Parodi Ga.

Glycine max (L.) Merr. Ala., Ariz.,

Matthiola sp.

$\frac{\text { Fragaria virginiana }}{\text { Duch. }}$

$\frac{\text { Lycopersicon esculentum }}{\text { Mill. }}$

Brassica napus L.

Vicia sp.

Triticum aestivum L. a. Ark., Fla., Ga., La. , Miss., N.C., S.C., Tex., Va.

Calif.

b.

Ala., Ark., Calif., Fla., Md., N.C., N.Y., Tenn., Va.

Fla., N.C., Tex.

a.

Ala., Ariz.,
Fla., Ga.

Tex.

a.

References

a.

a.

$a, b, f, l, m$, t.

$a, g g$.

$a, v$.

$a, g, i$, hh.

$a, f, h, m$.

Ala., Fla., $\quad a, h, m$.

Okla., Tenn., Tex. 


\section{MATERIALS AND METHODS}

\section{Rearing Techniques}

\section{General Methods}

Moths collected by Calvo (1966) in light traps near Gainesville, Florida, were the original stock for this investigation. Individuals from this stock were used to start a colony which was maintained for 7 months to establish a large colony before experimentation began. The colony was maintained for 27 months thereafter, representing a total of approximately 32 generations.

Several workers reared the insect thru its life history for 1 or 2 generations (Luginbill and Ainslie, 1917; Sanchez, 1950; King et al., 1961; Dupree, 1965; Leuck, 1966). Calvo (1966) reared several generations on a modification of Berger's (1963) diet for Heliothis sp. Larvae were reared individua!ly in vials. Macerated corn seedlings were added to the diet every 3rd generation to avoid pupal aberrations. Calvo (1966) collected eggs laid on paper thru screen topped cages -- the method adopted here.

Transparent plastic containers, $10 \times 10 \times 71 / 2 \mathrm{~cm}$ deep were used as matingoviposition cages (Fig. I A). Ten male and ten femole pupae were placed in each cage. A $14 \times 18$ mesh per inch galvanized screen stapled to a rim of woaden strips was placed over the cage mouth. Two percent sucrose solution was supplied in a wide-mouth pipette and soft rubber bulb (toial capacity $4 \mathrm{ml}$ ) placed thru a hole 
in the screen. This supply normally lasted 12 days. Immediately below the pipette was a dish $4 \mathrm{~cm}$ in diameter, held in place by masking tape in a rear floor corner. The dish trapped sugar solution that might drop from the pipette. If spilled solution coated the pupae, the adults could not emerge properly. Four mating-oviposition cages were prepared on each of 5 days during the week.

Each cage with pupae was numbered and put in a culture room at $47 \pm 1^{\circ} \mathrm{C}$, $30-50 \%$ relative humidity, and daily photoperiod of $13 \mathrm{hr}$ light. The pipette bulb was squeezed daily to release the air bubble that formed at the bottom, thus making the solution available to the emerged moths. After 1 of each sex had emerged, a paper sheet identified with the corresponding cage number was placed daily over the screen top. One corner of the egg sheet was folded upward to allow space for the protruding pipette bulb. The plastic cage top was placed diagonally over the sheet to hold it down. Eggs were laid on the sheet through the screen and were readily visible on the paper. After 7 of each sex emerged, this procedure was continued for 9 more days.

Egg sheets were removed daily and set aside on trays in the culture room for $24 \mathrm{hr}$. Egg color was used to differentiate between fertile and sterile eggs, since fertile eggs turned from cream white to red, while sterile eggs remained cream colored or furn red at 1 end only. The sheets were arranged in order on the basis of mating cage number and those with less than 30 eggs or more than $10 \%$ sterile eggs were discarded. To preserve genetic variability, the following system was used. Sixteen sheets were selected from the remaining egg sheets and divided into 4 groups of 4 each, with the lowest numbered sheet going to the lst group, the next highest to the 2 nd group, and so on until distributed. Then 25 fertile eggs were cut from 


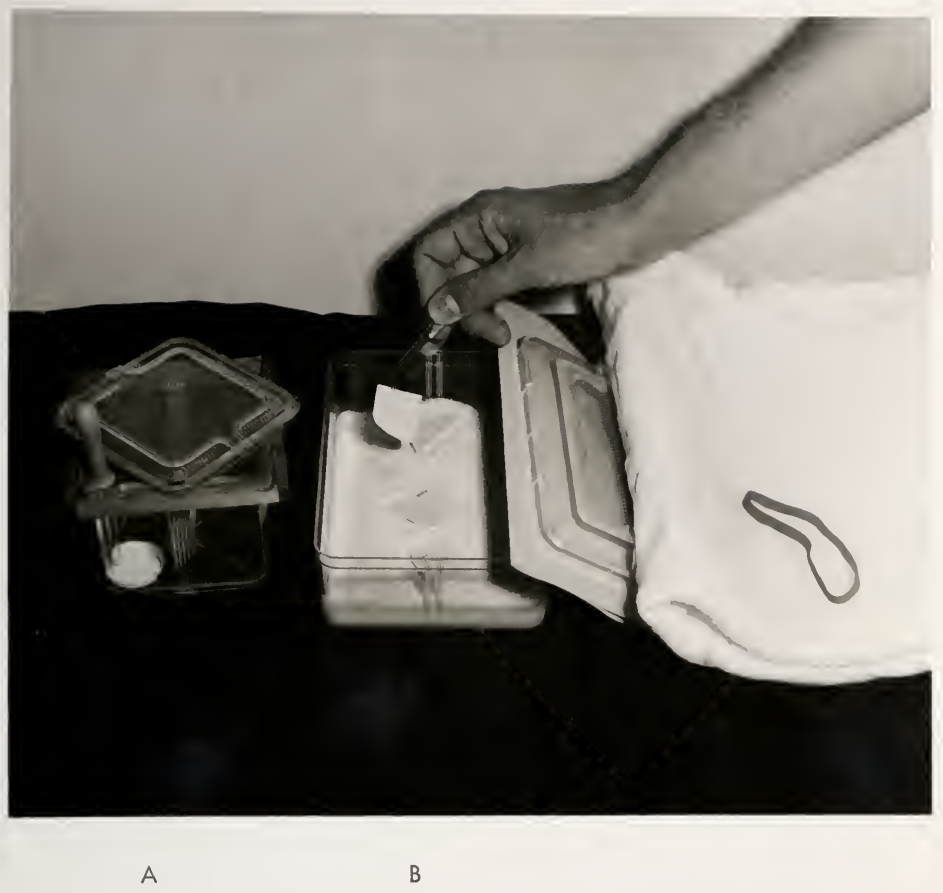

Fig. 1.-Cages used in rearing technique. A. Mating-oviposition cage. B. Rearing cage. 
each sheet and each group was put into a transparent plastic rearing cage. This cage (Fig. 1 B), $12 \mathrm{l} / 4 \times 17 \mathrm{l} / 4 \mathrm{~cm}$ by $6 \mathrm{~cm}$ deep was filled to about $12 \mathrm{~mm}$ depth with medium, modified from Berger (1963).

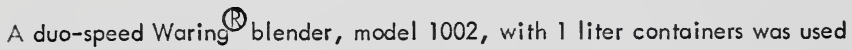
in media preparation. A blend was mixed in the order listed in Table 2. Blending was at low speed thru and including addition of alphacel. Previously measured ingredients were added without pause to avoid a highly viscous mixture. While the agar cooled to about $41^{\circ} \mathrm{C}$ after removal from the autoclave (about $3 \mathrm{~min}$, running cool tap water over the flask containing the agar), the blender was run continuously. The agar was then added with the blender running at high speed for the remaining blending. The total mixing process took 6-8 $\mathrm{min}$.

Medium prepared the day before use and placed under refrigeration was best, as fresh medium had somewhat more moisture than optimum. Any moisture that condensed on the sides of the container when it was removed from the refrigerator was wiped off. Otherwise, the water would cover the medium and ultimately kill the eggs, young larvae, or both. About $250 \mathrm{ml}$ of sifted, white, sterilized sand was foured down the long axis of each cage, and the sand ridge was leveled off, leaving the medium free of sand along the cage sides. The papers with 100 eggs of each group were placed on the sand ridges. Next a sterilized paper towel was placed over the cage rim, and a screen top was placed firmly over the towel. The screen top was made by cutting out the center of the plastic container top and replacing it with screen of the same mesh as used for the mating cages. The towel reduced evaporation and the screen top prevented larval escape. To reduce evaporation further, a $1.3 \mathrm{~cm}$ thickness of sterilized cellucotton was put over the screen top and held on with a large rubber band. 
Table 2. - Composition of medium for lesser cornstalk borer larvae.

Distilled water

$190.0 \mathrm{ml}$

$\mathrm{KOH}, 22.5 \%$

$4.3 \mathrm{ml}$

Casein, vitamin free

$40.0 \mathrm{~g}$

Wesson's salts

$8.5 \mathrm{~g}$

Sucrose

$22.7 \mathrm{~g}$

Formaldehyde, $10 \%$

$3.1 \mathrm{ml}$

Solution of: $7 \mathrm{~g}$ methyl $\mathrm{p}$-hydroxybenzoate and

$7 \mathrm{~g}$ sorbic acid in $50 \mathrm{ml} \mathrm{95 \%} \mathrm{ethyl} \mathrm{alcohol}$

$12.5 \mathrm{ml}$

Wheat germ

$25.6 \mathrm{~g}$

Alphacel (hydrolyzed purified cellulose, powder)

$4.3 \mathrm{~g}$

Agar, dissolved in $515 \mathrm{ml}$ water

$21.3 \mathrm{~g}$

Vitamin diet fortification mixture ${ }^{a}$

$8.5 \mathrm{~g}$

Ascorbic acid

$13.6 \mathrm{~g}$

Streptomycin sulfate (700 micrograms $/ \mathrm{ml}$ )

$118.0 \mathrm{mg}$

a Nutritional Biochemicals Corporation, Cleveland, Ohio 
After 21 days, the cage was opened, and the cellucotton, paper towel, and medium were removed. The screen top was replaced and used as a sieve for rapid separation of cocoons from the sand. The cocoons were hand picked from the remaining debris and placed in a small household sieve.

The sieve with the cocoons were dipped in dilute Chlorox ${ }^{(1)}$ solution (1 part chlorox to 1 part water) for $45-60 \mathrm{sec}$ and agitated to dissolve the silk and free the pupae (Bartlett and Martin, 1945). After rinsing the pupae in water, the pupae were dipped for $15-30 \mathrm{sec}$ in $60 \%$ isopropyl alcohol. The pupae sank and the larval exuviae were floated off. The pupae were spread on a paper towel to dry. Separation plus extraction took about $15 \mathrm{~min}$ per cage.

After extraction and drying, the pupae were sexed by examining the terminal abdominal segment (Fig. 2). Sexing was completed in $15 \mathrm{~min}$ per cage. Pupae were then selected for mating-oviposition cages. No more than 5 pupae and no more than 3 of 1 sex from a given rearing cage were put in 1 mating-oviposition cage. Pupae at the same developmental stage, judged by color, were placed in a given mating-oviposition cage so that adults would emerge about the same time. Four cages per day 5 days a week were prepared, numbered, and put in the culture room.

Females began ovipositing on the 2 nd night after emergence. During the 9 days that a mating-oviposition cage was kept, about $80 \%$ of the eggs that would be laid were deposited on the egg sheets. Colony daily egg production was about 5000. Duration of egg, larval, or pupal stages was not recorded as production of adults was the primary goal. Total time from egg deposition to adult emergence was 24-28 days. Larvae consumed about $1 / 10$ of the media. Production was low 


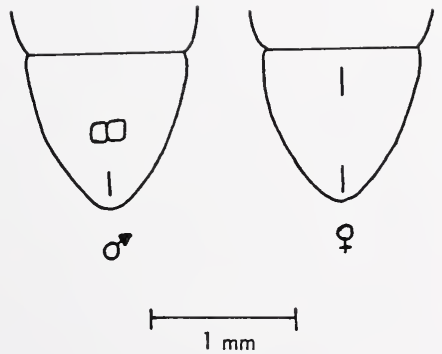

Fig. 2. - Ventral view of terminal pupal abdominal segments of the lesser cornstalk borer 
for the $1 \mathrm{~s}$ t few generations, but after a few generations, 60 to 80 pupae were obtained per cage.

The average duration from egg to adult, 26 days, was as short or shorter than results reported to date. Luginbill and Ainslie (1917) in South Carolina recorded 38.5 days for the spring generation, and 64.6 days for the fall generation under unspecified laboratory conditions, feeding larvae cowpea leaves. Spring temperatures ranged somewhere between $80-90^{\circ} \mathrm{F}$ diurnally and reached $80^{\circ} \mathrm{F}$ nocturnaily. Sanchez (1960) in Texas reported 24.3 days during August, and 46.3 days during September-October, feeding larvae peanut roots. Eggs were exposed to $70-100^{\circ} \mathrm{F}$. Larvae were exposed to the following average daily minimum and maximum temperatures: June, 77 and $92.3^{\circ} \mathrm{F}$; July, 79.5 and $93^{\circ} \mathrm{F}$; August, 79.5 and $94.5^{\circ} \mathrm{F}$; September, 74 and $89^{\circ} \mathrm{F}$. Pupcie were exposed to temperature ranges between the following minimum and maximum temperatures: July, $76-100^{\circ}$ F; August, $66-102^{\circ} \mathrm{F}$; September, 64 and $98^{\circ} \mathrm{F}$. No temperature ranges were mentioned for October. King et al. (1961) relied heavily on Sanchez for data and gave little detail on methods. Dupree (1965) in Georgia recorded 47.8 days and 55 days during June-September in 1957 and 1958, respectively, feeding larvae foliage and stem sections of seedling southern peas. Average minimum and maximum temperatures were 66.6 and $86.4^{\circ} \mathrm{F}$ in 1957 , and 66.8 and $88.2^{\circ} \mathrm{F}$ in 1958. Leuck (1966) in Georgia reported $32.8 \pm 2.8$ days, feeding larvae soybeans or cowpea leaves. Monthly mean minimum temperatures ranged from 57.4 and $72.7^{\circ}$ $\mathrm{F}$, monthly mean maximum 79.7 and $96.2^{\circ} \mathrm{F}$.

\section{Aberrant Pupae}

Calvo (1966) found after rearing 3 successive generations, a small but unspecified 
percentage of pupae appeared with poorly developed wing pads and light sclerotization over the pupal 3rd and 4th abdominal segments posterior to the wing pads. He found that the addition of macerated corn seedlings to the diet every 3rd generation eliminated pupal aberrations.

To determine the percent pupal aberrations and percent successful emergence from aberrant pupae occurring with my rearing technique after 23 generations, the following experiment was conducted.

Groups of pupae extracted on each of 6 days were examined. Aberrant pupae were described as below and place in numbered $4-d r$ vials, and the vials with pupae were placed in the culture room until adult emergence or death. Dead pupae became discolored and shriveled. Normal pupae not used in colany maintanence were used as controls and were handled in the same manner but not numbered.

All aberrations were on the pupal venter. These 4 categories were recognized: (A) a lightly sclerotized area between the $3 \mathrm{rd}$ and/or 4 th abdominal segment and the wing pads and appendages; (B) a lightly sclerotized area between the 3rd and/or 4 th abdominal segment and 1 or more appendages but not wing pads; (C) a lightly sclerotized area between 2 or more appendages or between a wing pad and appendage; and (D) 1 or more bright green appendages in an otherwise uniformly colored pupa.

Of 1721 pupae extracted, $5 \%$ of the male and $6 \%$ of the female pupae had aberrations. Fifteen percent of aberrant pupae exhibited 2 or more aberration types. Seventy-two percent of the males and $84 \%$ of the females emerged successfully, i.e., with wings fully expanded and with normally formed appendages. In the controls, $93 \%$ of the males and $92 \%$ of the females emerged successfully. 
The low percent pupal aberrations and the high percent successful emergence from aberrant pupae indicated the rearing technique was adequate.

\section{Other Materials and Methods}

Specific materials and methods are outlined under the appropriate sections below. However, a few general procedures that were used in several experiments are mentioned here.

Pupae not used to maintain the colony were placed in 4- $\mathrm{dr} 20 \times 70 \mathrm{~mm}$ glass shell vials, each with a small wad of cotton, and the vials were stoppered with cotton plugs. When moths emerged, the cotton wad was saturated with $2 \%$ sucrose solution. Adults were used the same day they emerged or were held in the 4-dr vials until they reached an age desired for experimentation.

In experiments involving mating and longevity of virgins, moths were placed in $4.7 \mathrm{~cm} \times 8.5 \mathrm{~cm} 40-\mathrm{dr}$ clear plastic vials. A wad of cellucotton was placed in the vial bottom and was saturated with $2 \%$ sucrose solution. The vial mouths were closed with squares of cellucotton $1 / 2 \mathrm{~mm}$ thick held in place with rubber bands. The vials with moths were then placed vertically in enameled pans and the pans with vials were placed in the temperature-controlled culture room. In experiments in which the moths were held for more than 4 days, clean vials and saturated cellucotton wads were provided daily.

All experiments were conducted in the same controlled temperature room at $47 \pm 1^{\circ} \mathrm{C}, 30-50 \% \mathrm{RH}$, and a daily photoperiod of $13 \mathrm{hr}$ light beginning at 7:00 AM.

With all morphological drawings, a stereoscopic microscope with an eyepiece grid was used in making measurements. 


\section{MORPHOLOGICAL STUDIES}

\section{Morphology of the Reproductive System}

In order to fully understand certain aspects of mating behavior, the internal reproductive morphology of the lesser cornstalk borer needed examination. The literature contains no reference to the subject. However, other workers have examined several related species, which are compared with E. lignosellus below.

\section{Materials and Methods}

Five 1-day-old adults of each sex were dissected in physiological saline consisting of $\mathrm{NaCl} 8 \mathrm{gm}, \mathrm{KCl} 0.2 \mathrm{gm}, \mathrm{CaCl}_{2} 0.2 \mathrm{gm}, \mathrm{H}_{2} \mathrm{O}$ to liter.

\section{Results and Discussion}

Male

The male reproductive systems of $\underline{E}$. lignosellus and the phycitid species Anagasta kuehniella (Zeller) (Mediterranean flour moth), Ephestia cautella (Walker) (almond moth), Ephestia ellutella (Hübner) (tobacco moth), and Plodia interpunctella (Hübner) (Indian-meal moth) (Norris, 1932) are very similar, but the ductus ejaculatorius simplex and cornutus of E. lignosellus differ from the others.

The unpaired ductus ejaculatorius simplex extends from the caudal end of the ductus ejaculatarius duplex (Fig. 3, D.e.d) to the aedeagus (Fig. 3, A). In the Noctuidae, Callahan (1958b) and Callahan and Chapin (1960) divided the duct 
into a cephalad primary secretory region and a caudad cuticular region where spermatophore precursors are molded. Later Callahan and Cascio (1963) divided the primary secretory region into the lst and 2 nd secretory areas. Norris (1932) histologically

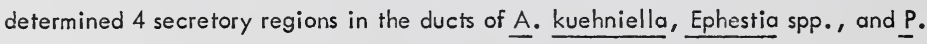
interpunctella, while Musgrave (1937) recognized 8 regions in A. kuehniella.

In E. lignosellus, 4 regions are present in the duct, based on exterior gross morphology (Fig. 3). They are described below using the terminology of Norris (1932) with the terminology of Callahan and Cascio (1963) in parentheses.

The lst region, which appears to include the lst 3 unpaired glands, $(=2$ nd secretory area of the primary simplex) extends approximately $11.5 \mathrm{~mm}$ (diameter, $0.15 \mathrm{~mm}$ ) from the ductus ejaculatorius duplex (Fig. 3, P.s.2).

The 2 nd region or 4 th unpaired gland (=1st secretory area of the primary simplex) extends $2.0 \mathrm{~mm}$ (diameter $0.2 \mathrm{~mm}$ ) (Fig. 3, P.s. 1). The region is not as greatly inflated with respect to the lst 3 unpaired glands in A. kuehniella, Ephestia spp., and $\underline{P}$. interpunctella.

The 3rd region or ductus ejaculatorius is $4 \mathrm{~mm}$ long (Fig. 3, D.e). The inflated 4 th region is the bulbus ejaculatorius (=cuticular simplex) (Fig. 3, B.e). The elongated horns of the ductus ejaculaforius of A. kuehniella, Ephestia spp., and $\underline{P}$. interpunctella are replaced in $\underline{E}$. lignosellus by 2 swollen structures in the same position as the horns (Fig. 3, I.c), adjacent to the aedeagus (Fig. 3, A).

The cornutus of E. lignosellus is a slender curved tooth (Fig. 3, C) differing from the thickened teeth of various shapes of $\underline{A}$. kuehniella, Ephestia spp., and $\underline{P}$. interpunctella.

The morphology of the testes of E. lignosellus is the same as in A. kuehniella, 


\section{Explanation of Fig. 3}

Terminology mostly after Norris (1932)

Terminology after Callahan and Cascio (1963) in parentheses

\section{A Aedeagus}

A.g Acessory glands

B.e Bulbus ejaculatorius (of cuticular simplex) of ductus ejaculatorius simplex

C Cornutus

D.e Ductus ejaculatorius of ductus ejaculatorius simplex

D.e.d Ductus ejaculatorius duplex

E Endophallus

I.c Inflated chambers of ductus ejaculatorius (of cuticular simplex) of ductus ejaculatorius simplex

P.s. 1 (1st secretory area of the prinary simplex) of ductus ejaculatorius simplex

P.s.2 (2nd secretory area of the primary simplex) of ductus ejaculatorius simplex

S.v Seminal vesicle

T Testes

V.d Vas deferens 


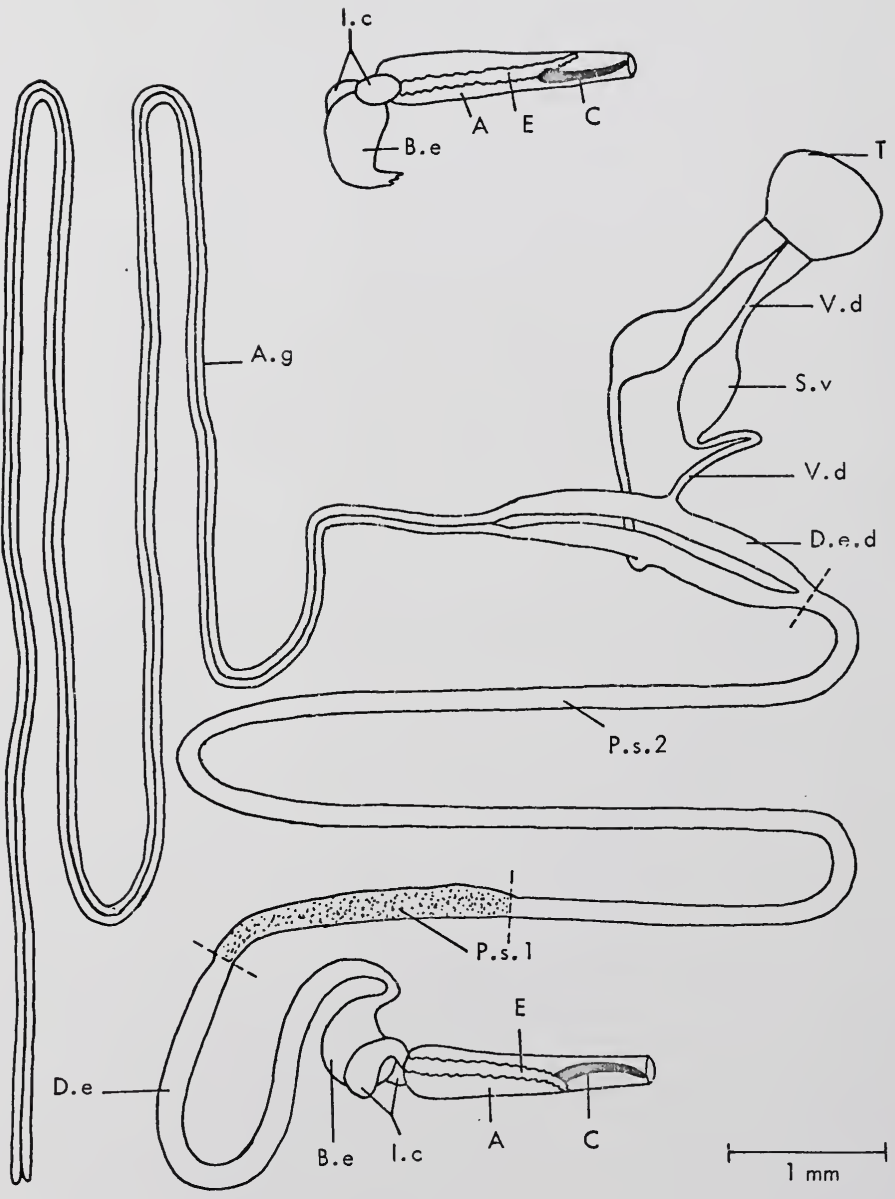

Fig. 3.-Reproductive system of the mole lesser cornstalk borer 
Ephestia spp., and $\underline{P}$. interpunictella. Cholodkovsky (1884) recognized 4 groups of Lepidoptera based on testes types: (A) testes completely separate and 4-lobed, as in Hepialus; (B) testes separcte but rounded and 3-lobed, as in Saturnia; $(C)$ discernibly separate testes enclosed in a single scrotum, as in Lycaena; and (D) testes fused and appearing as a single round organ in a common scrotum, as in Pieris. All phycitid species previously mentioned belong to group $D$.

Female

The female reproductive system of $\underline{E}$. lignosellus differs in several details from the phycitid species by Norris (1932).

The bursa copulatrix of the lesser cornstalk borer consists of a sac, the corpus bursae (Fig. 4, C.b), and a neck, the ductus bursae (Fig. 4, D. b), and opens externally and ventrally thru the ostium bursae (Fig. 4, O.b) on the 8th sernite. The corpus bursae bears a large dorsal and small ventral plate bearing approximately 25 and 53 teeth or signa respectively (Fig. 4, D.p.s and V.p.s), which project into

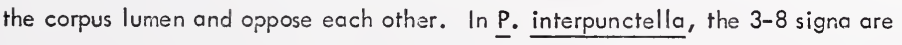
arranged on the dorsal wall of the corpus, while A. kuehniella has 2-4 signa on the ventral wa!l only.

The ductus seminalis in E. lignosellus (Fig. 4, D.s) is of uniform diameter for its entire length and apparently lacks a bulla seminis. The duct enters the corpus bursae at a projection on the caudal end of the corpus. In A. kuehniella, Ephestia

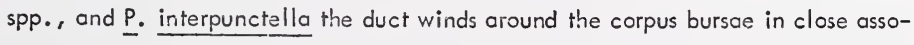
ciation with the corpus wall and opens into the corpus adjacent to the signa, about $1 / 3$ the corpus length from the cephalad end.

The glandula receptaculi of E. lignosellus (Fig. 4, G.r) is an elongate simple 


\section{Explanation of Fig. 4}

Terminology after Norris (1932)

A.g Accessory gland

C Calyx

C.a.g Common duct of accessory gland

C.b Corpus bursae

C.o Common oviduct

D.b Ductus bursae with longitudinally ribbed sclerotization

D.p.s Dorsal plate with signa

D. $\mathrm{r}$ Ductus receptaculi

D.s Ductus seminal is

G.r Glandula receptaculi

I.v Inflated part of vestibulum wall

L.a.g Laterol duct of accessory gland

L. $0 \quad$ Lateral oviduct

M Membrane surrounding the bursae copulatrix and the ductus seminalis

O.b Ostium bursae

Ovar Ovariole

Ovip Ovipositor

R.a.g Reservoir of accessory gland

T. $v \quad$ Terminal vesicle

Va Vagina

Ve Vestibulum

V.p.s Ventral flate with signa 


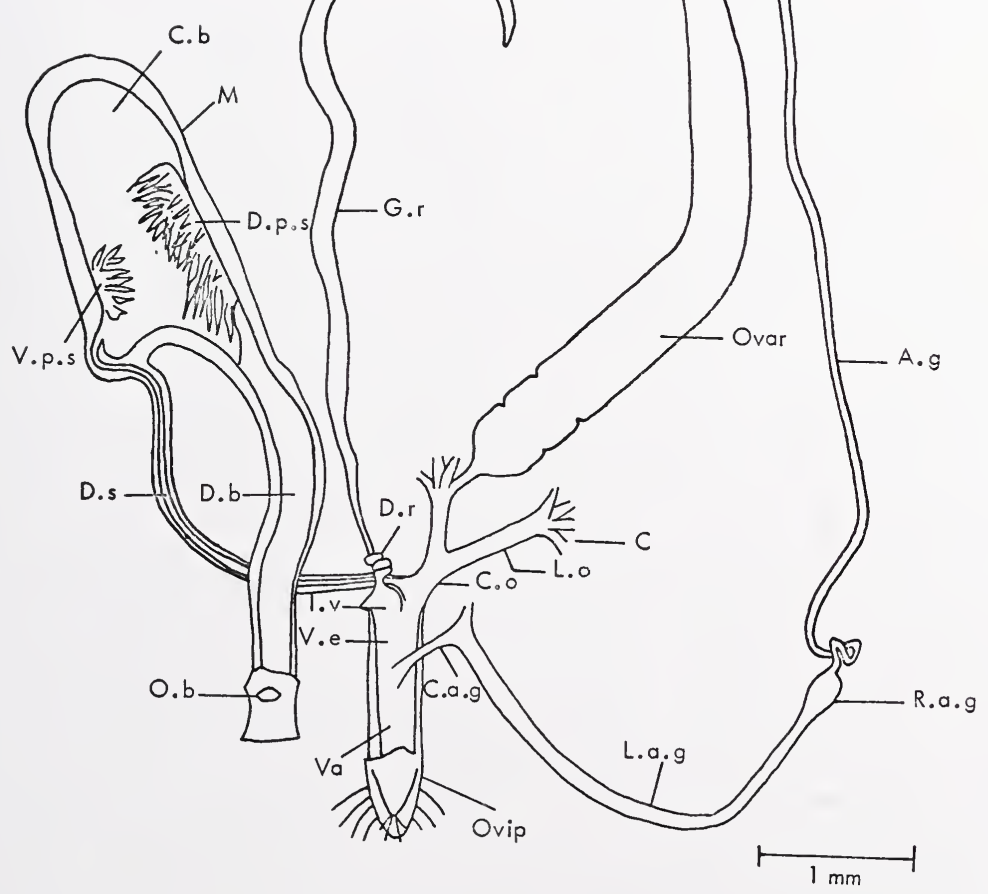

Fig. 4.-Reproductive system of the female lesser cornstalk borer 
structure tapering caudally and leading to the coiled ductus receptaculi (Fig. 4, D.r) which in turn opens into a hemispherical inflated portion of the dorsal vestibulum wall (Fig. 4, I.v). In $\underline{P}$. interpunctella, the gland is nearly always simple. In A. kuehniella it is often bifurcated at the tip, and one branch may be shorter than the other. In both species, the gland opens into a caudal sac, the receptaculum seminis, which leads to the ductus receptaculum.

The lesser cornstalk borer accessory glands (Fig. 4, A.g) are elongate structures leading to a series of convolutions that ultimately open into the oval-shaped reservoirs (Fig. 4, R.a.g) which in turn open into narrow ducts leading to the common accessory gland duct (Fig. 4, C.a.g). In A. kuehniella, Ephestia spp., and $\underline{P}$. interpunctella, the reservoirs are elongate structures with the greater part of the caudal lengths dilated.

\section{The Spermatophore}

During a successful mating, the Lepidoptera transfer sperm in a spermatophore formed from secretions in the male ductus ejaculatorius simplex (Callahan, 1958b). Even within families, the spermatophore shape varies greatly (Williams, 1941), and formation and transfer mechanisms are sometimes highly complex (Callahan, 1958b).

A spermatophore of A. kuehniella, E. cautella, E. elutella, or $\underline{P}$. interpunctella consists of a rounded corpus with a narrow twisted collum ending in a frenum. Solid horns on the frenum correspond exactly in number and arrangement with species specific structures of the ductus ejaculatorius. The sperm escape thru an oval aperfure in the frenum with the aperture at the ductus seminalis entrance (Norris, 1932). Petersen (1907) found that Lepidoptera with ductus seminalis apertures distal on the ductus bursae produce spermatophores with long collums. Where the aperture 
appears in the corpus bursae, collums are either short or twisted beside the spermatophore corpus, as in Anagasta, Ephestia, and Plodia (Norris, 1932).

Williams (1941) divided the Heterocera into 3 groups based on spermatophore communication in the female reproductive system: (A) spermatophores in direct communicotion with the ductus seminalis, which are found in the majority of the moths; (B) spermatophores communicating with a duct leading to a secretion filled reservoir opening into the ductus seminalis which leads from the reservoir to the vagina, which are found in some arctiids and tortricids; and (C) spermatophores opening into the ductus bursae which extends to the vagina, which are found only in the primitive prodoxids.

Stitz (1901) believed the signa punctured the spermatophore, but Williams (1938) believed spermatophores were dissolved by enzymes in the ductus bursae. Callahan (1958b) stated that there is no evidence for either of these beliefs. He felt Petersen's (1907) theory that the signa serve to hold the smooth plastic-like spermatophore in place is probably correct.

The empty spermatophores in female potato fuberworm moths, Phthorimaea operculella (Zeller), are forced anteriorly in the corpus bursae when multiple mating occurs (Hughes, 1967). Severa! are found collapsed and nested within each other, while the most recently deposited spermatophore occupied the corpus bursae posteriorly.

The purpose of this section is to present the spermatophore morphology of $\underline{E}$. lignosellus, its position in the corpus bursae, the probable mode of sperm escape from the spermatophore, and the fate of empty spermatophores. 
Materials and Methods

Five spermatophores representing ist matings by both males and females were dissected from females and placed in physiological saline. During dissections, the spermatophore orientation in the corpus bursae was observed.

The spermatophores in multiple mated females were observed in moths taken from 4 mating-oviposition cages. Thirty-two females had 2-5 spermatophores in the corpus bursoe.

\section{Results and Discussion}

The spermatophore is illustrated in Fig. 5 . The frenum bears 2 small rounded projections that seem to correspond to the inflated chambers on the male ductus ejaculatorius (Fig. 3, I.c). The aperture thru which sperm escape is terminal and between the 2 rounded projections.

The 2 toothed plates of the corpus bursae walls tightly hold the spermatophore in place. The collum is twisted and pressed against the posterior lateral wall of the corpus bursae, and the frenum with its aperture is in direct contact with the ductus seminalis. Thus the lesser cornstalk borer belongs to Williams' (1941) group A.

As in the potato fuberworm moth (Hughes, 1967), when multiple mating occurs, empty spermatophores are forced anteriorly in the corpus bursae flottening and/or nesting into one another. The most recently deposited spermatophore is held tightly between the 2 plates of signa, which seems to support Petersen's (1907) theory of signa function. No spermatophores were punctured and none showed evidence of being dissolved. Callahan (1958b) found striated muscle tissue surrounding the corpus bursae wall of Heliothis zea (Boddie) and theorized constriction of the muscle 


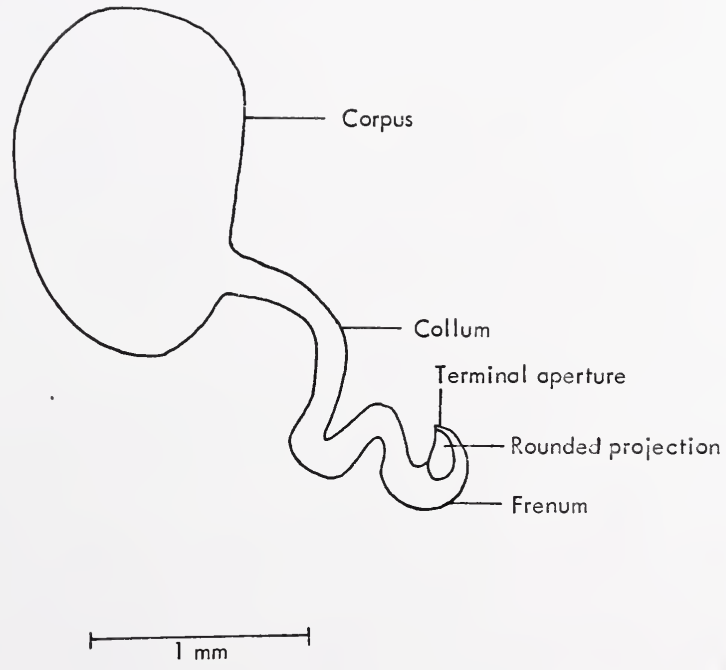

Fig. 5. -Spermatophore of the lesser cornstalk borer 
exerted pressure on the spermatophore corpus, thereby forcing sperm out of the structure. This may be the mode of sperm escape from lesser cornstalk borer spermatophores.

\section{Primary Simplex and Spermatophore Color}

Snow and Carlysle (1967) reported that the lst secretory area of the primary simplex in a virgin male fall army worm, Spodoptera frugiperda (J. E. Smith), is filled with a light brown to black fluid. During mating, portions of the pigment are passed to the female corpus bursae, while the remainder is incorporated into the spermatophore, resulting in a darkly pigmented spermatophore. The simplex is left transparent and colorless-to-yellow. A darkly pigmented spermatophore and a transparent, colorless-to-yellow simplex together indicate a lst mating for the male. Subsequent spermatophores are clear to yellow.

The technique is limited by age. Newly emerged males have light to medium brown pigment in the simplex. Males mating once and retained 4 days after removal of females have transparent, yellow, or light brown pigment. Virgins of this age have dark brown to black pigment in the simplex and hence are distinguishable from mated males.

The purpose of this experiment was to determine if a color change of the primary simplex fluid indicates a male has mated within $24 \mathrm{hr}$, and if so, how long the resulting color is retained. Spermatophore color was checked to see if those passed Ist differed from those passed subsequently.

Materials and Methods

Each of 182 3-day-old males were caged with two 3-day-old females for 1 
day. The females were dissected for spermatophores. Males were dissected for determination of simplex color in the morning, afternoon, or evening.

The above experiment indicated virgin males tend to have translucent yellow simplex fluid, while mated males had transparent, colorless-to-yellow fluid. To test this further the following experiments were conducted.

Twenty-five each of 1-, 2-, and 3-day-old virgin males and 10 each of 4-, 5-, and 6-day-old virgin males were dissected for determination of simplex fluid color and light transmission.

Thirty 1-day-old virgin males were caged individually with two 1-3-day-old virgin females for 1 day. Females were dissected for spermatophores. Ten mated males were retained 2,4 , and 5 days after removal of females. Five males of each group were dissected for determination of simplex fluid color and light transmission between 9-11 AM and 5 were dissected between 9:30-11 PM.

Ten 1-day-old virgin males were individually caged with two 1-3-day-old virgin females. Females were replaced daily by two 1- to 3 -day-old virgin females for 3 days. Females were dissected for spermatophores and the color of lst and subsequent spermatophores was compared. Five males were dissected for determination of simplex fluid color and light transmission at 11 AM and 5 at 9:30 PM.

Materials and methods for further data on simplex color and light transmission and spermatophore color are presented in the section below dealing with mating behavior.

Results and Discussion

Table 3 indicates a progressive color change in simplex fluid color of 3-day-old 
males within $24 \mathrm{hr}$ after mating. All spermatophores were clear and transparent.

Simplex fluid color was translucent cream-yellow to yellow in 1- to 3-dayold virgin males and tronslucent yellow in virgin 4- to 6-day-old males.

All mated males retained for 2,4 , and 5 days after removal of females had transparent yellow simplex fluid. Six males not mating the day of caging had translucent yellow fluid the following day.

Nine males mated on each of 3 days when caged with females 3 days. Four males dissected in the morning had transparent colorless simplex fluid. One male failed to mate the 3rd night and had transparent pale yellow simplex fluid. All males dissected in the evening had transparent pale yellow simplex fluid. All spermatophores passed on the 3 nights were clear and transparent.

The above indicates that mated males can be distinguished from virgin males by transparent versus translucent simplex fluid for at least 5 days after mating. A mating during the previous night is indicated by transparent colorless simplex fluid. Color of 1st, 2nd, and 3rd spermatophores passed successively on 3 nights is identical and does not distinguish between lst and subsequent matings.

Data from the section below dealing with mating behavior indicated the primary simplex fluid of 1-day-old males was colorless and transparent in all mated males and translucent yellow in 2 unmated males. Apparently 1-day-old mated males can be distinguished from unnated males of the same age within $3 \mathrm{hr}$ of mating.

\section{Egg Development and Position Relative to Age}

The Lepidoptera show considerable variation in egg development at emergence. Eidmann (1931) placed the Lepidoptera in 3 groups based on the number of fullsized eggs in the ovaries at adult emergence: (A) species with very few full-sized 
Table 3.-Color of fluid in the $1 \mathrm{~s} t$ secretory area of the primary simplex of 3-day-old mated and unmated lesser cornstalk borer males at different periods of the day following mating the previous night.

\begin{tabular}{|c|c|c|c|c|c|c|}
\hline \multirow{2}{*}{$\begin{array}{l}\text { Time of } \\
\text { dissection }\end{array}$} & \multirow{2}{*}{$\begin{array}{l}\text { Sample } \\
\text { Size }\end{array}$} & \multicolumn{3}{|c|}{ Color of simplex (\%) } & \multicolumn{2}{|c|}{$\begin{array}{l}\text { Unmated Males } \\
\text { CoTor of simplex }(\%)\end{array}$} \\
\hline & & Clear & Pale-yellow & Yellow & PaTe-yellow & Yellow \\
\hline $7-12$ AM & 51 & 84 & & & & 16 \\
\hline $2-3 P M$ & 21 & 57 & 5 & & & 38 \\
\hline 7- $9 P M$ & 46 & 33 & 35 & 8 & 2 & 22 \\
\hline $9-11$ PM & 64 & & 50 & 23 & & 27 \\
\hline
\end{tabular}


eggs at emergence, typical of butterflies and moths with a long adult life; (B) species having a 2-or 3-fold increase in full-sized eggs in the imago, as with most Heterocera; and (C) species with all eggs fully developed at emergence, as in the Bombycidae and Lymantriidae.

Full-sized eggs are present in ovaries of newly emerged A. kuehniella females, but none are present in $\underline{P}$. interpunctella females at emergence (Norris, 1932).

The purpose of this experiment was to determine the stage of egg development and egg position in the reproductive tract of virgin females relative to age.

Materials and Methods

Moths $0-8 \mathrm{hr}$ old and 1 and 2 days old were retained individually in 4-dr vials until dissected in distilled water. Moths were classified into 4 groups; (A) moths with full-sized eggs in the common oviduct, lateral oviducts, calyx, and ovarioles; (B) moths with full-sized eggs in the lateral oviducts, calyx, and ovarioles only; (C) moths with full-sized eggs in the calyx and ovarioles only; and (D) moths with no full-sized eggs. The number of visible eggs in the ovarioles of 0-8-hr-old females were recorded.

\section{Results and Discussion}

No full-sized eggs were present in 0-8-hr-old females (Fig. 6) which would place the lesser cornstalk borer in Eidmann's (1931) group A. However, the moth's life span is relatively short (8-22 days) under outside conditions (Dupree, 1965; Leuck, 1966). An average of 26 eggs were visible per ovariole.

Unlike H. zea (Callahon, 1958b), some E. lignosellus virgin 1-day-old females 


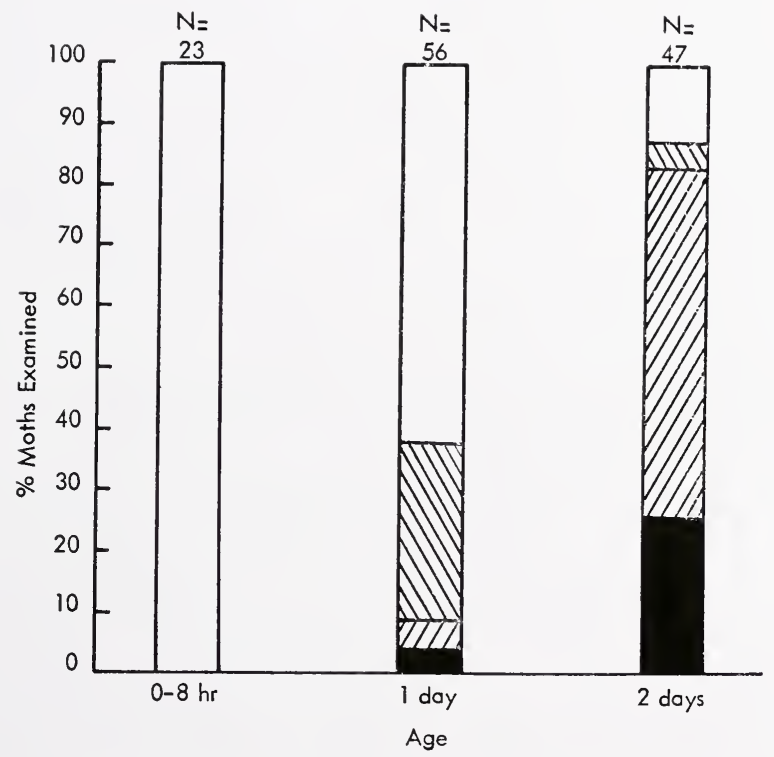

Group A. Fult-sized eggs in common oviduct, lateral oviducts, calyx, and ovarioles

DJ Group B. Full-sized eggs in lateral oviducts, calyx, and ovorioles only

WV Group C. Full-sized eggs in calyx and ovorioles only

$\square$ Group D. No full-sized eggs

Fig. 6. - Egg development and position in reproductive tract of lesser cornstalk borer virgin females relative to age 
developed full-sized eggs which appeared in the common oviduct, lateral oviducts, and/or calyx (Fig. 6).

\section{Morphology of the Tympanic Organ}

The lesser cornstalk borer has tympanic organs. Thoracic and abdominal tympanic organs are found in 11 families of Lepidoptera within the Noctuoidea, the Geometroidea, and the Pyraloidea. As far as known, they are lacking in all other groups (Bourgogne, 1951). The thoracic type is confined to the Noctuoidea, and is considered monophyletic by Kiriakoff (1963). The abdominal organs are divided into 3 groups and appear on the 1 st or 2 nd segments in the Pyraloidea, the Geometroidea, and the Drepanoidea. The abdominal types cre poorly known but appear polyphyletic in origin. Eggers $(1919,1925,1928)$ ard Kennel and Eggers (1933) published extensive works on the abdominal organs, but in recent years, these organs have been ignored (Kiriakoff, 1963).

In the Pyraloidea, tympanic organs are found in the lst abdominal segment, and are often obscure externally since the tympani face the thorax (Bourgogne, 1951). Tympanal cavities are shallow or essentially absent. Principal tympani are situated ventraliy on the modified anterior portion of the lst abdominal sternites (sternites 1 and 2), and are separated by a strongly scaled and sclerified longitudinal band. The band frequently continues posteriorly in 2 large projecting lobes that sometimes serve as tympanal opercula. Each tympanic organ has a tympanal sac enclosed in a chitinous hemisphere formed by integumental invagination. Its walls are formed by 2 lamellae which remain completely separated, or may be partly or completely closed. The scolophore (=scolopophorous organ), containing 4 scolopalia, may extend from the tympanum to the hemisphere surface 
or to an internal ridge. In some subfamilies, as many as 5 accessory tympani may be present: (A) a single dorsal tympanum composed of a thin metapostnotal ridge; (B) a pair of lateral tympani on the metathoracic epimera or on either side of the metapostnotum; and (C) a pair of coxal tympani on the posterior face of the metathoracic coxae.

Materials and Methods

Five 1-day-old adults of each sex were dissected in distilled water. The thorax was separated from the abdomen, and the lst abdominal segment bearing the tympanic organs was separated from the remaining abdominal segments. This permitted an unobstructed view of the anterior surfaces. To expose internal structure, an incision was made just posterior and lateral to the anterior margin of the right organ.

\section{Results and Discussion}

Figs. 7 and 8 illustrate the external and internal structure of the organs.

There is no sexual dimorphism in the organ structure. The tympanal cavity is essentially absent since only narrow ridges (Fig. 7, S.r) circumscribe the anterior surface of the lst abdominal segment. The tympanal sacs (Fig. 8) and tympani (Fig. $7, T$ ) are separated by a strongly scaled and sclerified longitudinal band (Fig. 7, S.I.b) which terminates ventral to the oriface thru which the internal organs pass (Fig. 7,0 ). The metathoracic coxae and the scales on the longitudinal band obscure the tympanal surface externally. The principle tympani are ventrally located, and the presumed scolopophorous organs, easily seen thru the thin tympanal integument, pass ventrally from the tympanic surface to an internal 
ridge (Fig. 8) which leads to the mesal surface of the tympanal sac. Two completely separate lamellae form the tympanal sac wall. Integumentary folds possibly formed from the metathoracic epimera overlap the tympanic suifaces and form presumed accessory tympani (Fig. 7, A.t).

The tympanic organ structures of $\underline{E}$. lignosellus agree with the general pyraloid described above. 


\section{Explanation of Fig. 7}
A.t Accessory tympanum
O Orifice for internal organs
T Tymponum
S.r Sclerotized ridge
S.O Scolophophorous organ
S.I.b Sclerotized longitudinal band 

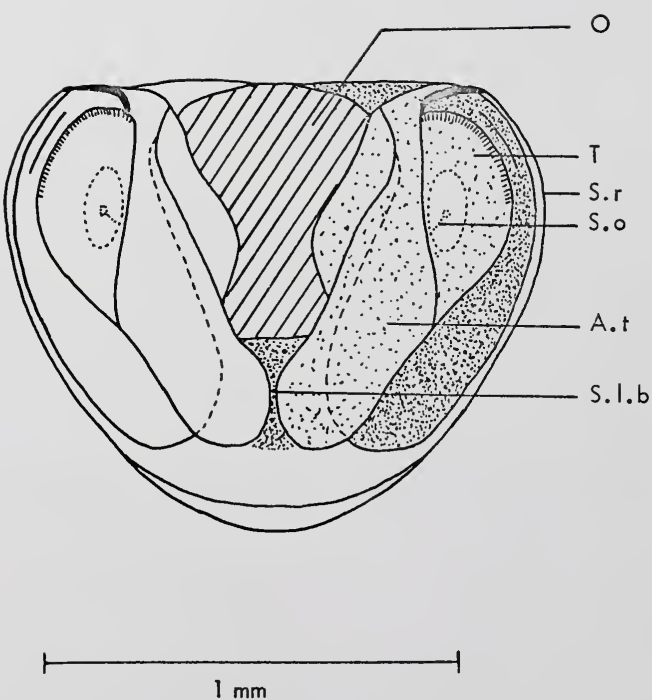

Fig. 7. - External anterior view of the first abdominal segment of the lesser cornstalk borer moth illustrating the tympanic organs on the excised abdomen 


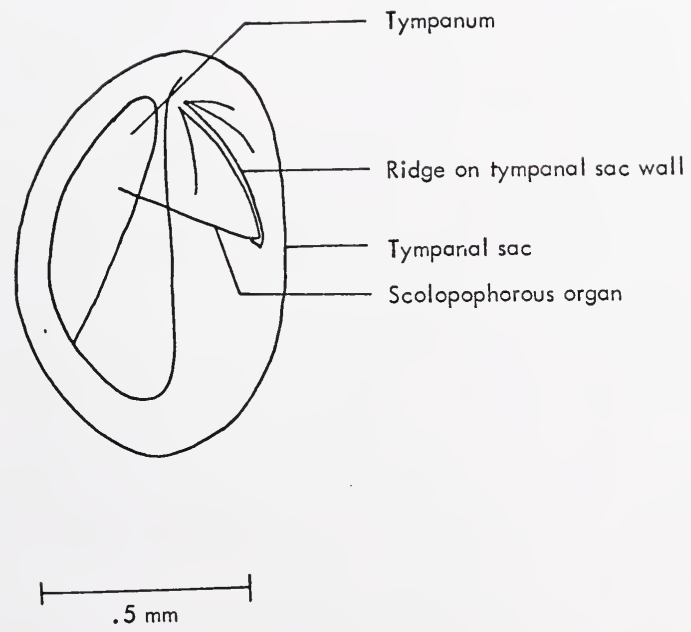

Fig. 8-Internal lateral view of the right tympanic organ of the lesser cornstalk borer with the lateral wall of the tympanal sac removed 


\section{BEHAVIORAL STUIDIES}

\section{Mating Cage Conditions}

Workers used various mating cage conditions. Luginbill and Ainslie (1917) used glass lantern chimneys of unspecified size in mating and oviposition studies with single pairs. They stated that fed moths lived longer than starved, but did not distinguish between the 2 groups in their data. Dupree (1965) mated pairs of moths in $30 \times 100$ $\mathrm{mm}$ shell vials with about $30.0 \mathrm{cc} / \mathrm{moth}$, and fed them honey diluted with 1 part water adding sodium benzoate to prevent spoilage. Leuck (1966) retained an unspecified number of moths in a $1 \mathrm{cu} f t$ polyethylene covered mating cage, and fed them $10 \%$ honey-water. Calvo (1966) retained 35 moths of each sex in a screen cage with $113.8 \mathrm{cc} /$ moth. No mating occurred unless there were 5 moths of each sex per cu ft. Stone (1968) used 10 moths of each sex per mating-oviposition cage with 30.3 $\mathrm{cc} /$ moth. Both Calvo and Stone fed moths $2 \%$ sucrose solution.

The purpose of this experiment was to find a convenient cage size with acceptable top material and cage placement for mating behavior studies, and to determine if fed and unfed moths mated with equal frequency.

\section{Materials and Methods}

Vials of 4- and 40-dr were tested as mating eages. In each of ten 4-dr vials, 1 pair of 1-day-old (0-24 hr) moths and a cotton wad were placed. The cotton wads 
were left dry in 5 vials and saturated with $2 \%$ sucrose solution in 5 vials. Saturated cotton wads were resaturated when nearly dry. All vials were stoppered with cotton plugs, placed horizontally, and held for 6 days. Further tests with fed moths in 4-dr vials involved 6 pairs of 1-day-old moths for 5 days, 4 pairs of 2-day-old moths for 7 days, and 4 pairs of 3-day-old moths for 7 days.

In the 40-dr vials, mating frequency of fed versus unfed moths was compared. In addition, screen versus cellucotton tops and vertical versus horizontal vial placement were tested concurrently using a series of 176 vials. The influence of water versus the $2 \%$ sucrose solution on mating frequency was not tested. In each of the 176 vials, 1 pair of 2-day-old moths was held 4 days. In 88 of these vials, the cotton wad was saturated with $2 \%$ sucrose solution, in the other 83 vials they were left dry. Forty-four of each set of 88 were closed with squares of $14 \times 18$ mesh/in fiberglas screen held in place with rubber bands, while the other 44 were closed with squares of cellucotton $1 / 2 \mathrm{~mm}$ thick held in place with rubber bands. Lastly, each set of 44 vials was again divided with 22 held vertically and 22 held horizontally.

At the end of each test, females were dissected for spermatophores.

\section{Results and Discussion}

No mating occurred in 4-dr vials, where available space was $7.2 \mathrm{cc} /$ moth. Uncler fed versus unfed conditions, 1 fed female, 3 unfed males, and 1 unfed female died.

Mating occurred in the $40-\mathrm{dr}$ vials, where available space was $29.5 \mathrm{~cd} / \mathrm{moth}$ (Table 4). Chi square analysis of the multiple factor test indicated no significant difference at the $1 \%$ level among position, cage top material, and fed versus 
Table 4.-Cage conditions and spermatophores passed by 2-day-old fed and unfed lesser cornstalk borer adults, tested for 4 days in 40-dr vials, 1 pair per vial, 22 replicates per test.

\begin{tabular}{|c|c|c|c|c|c|c|}
\hline Conditions & $\begin{array}{l}\text { No. } \\
\text { moths } \\
\text { dead }\end{array}$ & $\begin{array}{c}\text { Cages } \\
\text { without } \\
\text { mating }\end{array}$ & $\begin{array}{c}\text { Cages } \\
\text { with } 1 \text { or } \\
\text { more sprmts. }\end{array}$ & $\begin{array}{r}\text { Multi } \\
\text { matir } \\
\text { sprmts. }\end{array}$ & $\begin{array}{l}\text { ple } \\
\text { igs } \\
\text { cages }\end{array}$ & $\begin{array}{c}\text { Total } \\
\text { sprmts. } \\
\text { passed } \\
\end{array}$ \\
\hline \multicolumn{7}{|c|}{ Fed ( $2 \%$ sucrose) } \\
\hline Screen top, & 0 & 10 & 12 & 2 & 2 & 20 \\
\hline vertical & & & & 4 & 2 & \\
\hline Screen top, & $10 m^{a}(2)^{b}$ & 10 & 12 & 2 & 5 & 19 \\
\hline horizontal & & & & 3 & 1 & \\
\hline Cellu. top, & 0 & 6 & 16 & 2 & 4 & 27 \\
\hline \multirow[t]{2}{*}{ vertical } & & & & 3 & 2 & \\
\hline & & & & 4 & 1 & \\
\hline Cellu. top, & 0 & 8 & 14 & 2 & 5 & 22 \\
\hline \multirow[t]{2}{*}{ horizontal } & & & & 4 & 1 & \\
\hline & & \multicolumn{2}{|c|}{ Unfed (No sucrose) } & & & \\
\hline Screen top, & 8 రิธి & 12 & 10 & 2 & 2 & 12 \\
\hline vertical & $19(0)^{b}$ & & & & & \\
\hline Screen top, & 10 రิరి & 10 & 12 & 0 & & 12 \\
\hline \multicolumn{7}{|l|}{ horizontal } \\
\hline Cellu. top, & 680 & 6 & 16 & 0 & & 16 \\
\hline \multicolumn{7}{|l|}{ vertical } \\
\hline $\begin{array}{l}\text { Cellu. top, } \\
\text { horizontal }\end{array}$ & 5 केष & 12 & 10 & 2 & 1 & 11 \\
\hline
\end{tabular}

$a_{\text {mates attached when cage dismantled }}$

$b_{\text {number of spermatophores accepted }}$ 
unfed moths for a single mating per pair. Fed moths had highly significantly more multiple matings than unfed maths. Twenty-nine unfed males died while no fed males died during the tests.

Forty-dr vials were thus considered adequate for mating studies. Moths should be given sugar solution to avoid death within 4 days if the moths are retained for several days, or if multiple matings are desirable.

\section{Mating Behavior}

The mating behavior of the lesser cornstalk borer has not been reported in the literature. Luginbill and Ainslie (1917) assumed mating occurred the 2nd night after emergence. Leuck (1966) stated that moths were most active in the field after dark in still air with low humidity at temperatures exceeding $80^{\circ} \mathrm{F}$. He felt these conditions were optimum for mating and oviposition.

A. kuehniella and $\underline{P}$. interpunctella females "call" prior to mating, that is, the abdomen is bent dorsally between the wings and the ovipositor is alternately protruded and retracted. Calling by $\underline{\underline{P}}$. interpunctella females is not correlated with egg development since it occurs before and after full-sized eggs are present, and after al! eggs are laid (Norris, 1932).

Richards and Thomson (1932) reported mating behavior in a general discussion of the genera Ephestia, Anagasto, and Plodia, but made no reference to behavior of a given species. Receptive females begin calling with the apical half of the abdomen bent dorsally between the wings. The ovipositor is alternately protruded and retracted. A male begins fluttering around the female which does not respond or runs avray. Eventually the female stops, the male faces her head to head and bends his abdomen dorsally ond anteriorly to grip the female abdomen tip. Quickly 
the pair twists around and assumes an end to end copulatory position.

Williams (1938) stated that the A. kuehniella female calls with the wings spread and the abdomen curved upward until mating occurs. Females are quiet (=stationary?) when calling. The male moves about vibrating his wings until he meets a female. He then curls his abdomen towards her and couples.

Schwink (1953) reported that $\underline{A}$. kuehniella and $\underline{P}$. interpunctella males respond to the ir respective females with long-lasting whirrings. Whirs lasting 40 sec to several minutes are separated by short pauses and occur many times within several hours.

Brindley (1930) stated that copulation of A. kuehniella occurs after midnight the day of emergence, and lasts 4-6 hr. Norris (1932) reported that copulatory duration of $\underline{A}$. kuehniella is $3-4 \mathrm{hr}$, and $1-1 \mathrm{l} / 2 \mathrm{hr}$ for $\underline{P}$. interpunctella. Williams (1938) reported that copulation lasts $3-5 \mathrm{hr}$ for A. kuehniella.

The purpose of this experiment was to observe pair formation and courtship of E. lignosellus, time of coupling, duration of copulation, uncoupling of mates, and post copulatory activity. In addition the following factors were observed: number of spermatophores passed per mating; and egg development and placement of fullsized eggs in the reproductive tract of mated and unmated females.

Materials and Methods

Pairs of 1-day-old moths were placed in each of 5 clear plastic containers, $12 \mathrm{l} / 4 \mathrm{~cm} \times 17 \mathrm{~V} / 4 \mathrm{~cm} \times 6 \mathrm{~cm}$ deep. Cellucotton squares, $3 \mathrm{~mm}$ thick and $4 \mathrm{~cm}$ on a side, were folded in $3 r d s$, saturated with $2 \%$ sucrose solution, and placed in the left back corner of the cage floors. The cage mouths were covered with 2-mmthick cellucotton held to the uppermost cage perimsters with rubber bands to permit 
maximum visibility. Cages were set on platforms composed of 2 containers, identical to the cage, stacked on top of each other and separated from other platforms by $28 \mathrm{~cm}$. One $\mathrm{ft}$ behind each cage was a $71 / 2$ watt red light with a reflector which illuminated the cages at about $1 \mathrm{ft}$-candle. The main lights were turned out and the red lights turned on at 8:00 PM.

The laboratory temperature during experimentation was $45.5 \pm 3^{\circ} \mathrm{C}$ both nights. The lst night, the relative humidity control was turned to capacity at 8:00 PM and turned off at midnight. Before the experiment, humidity was $46 \%$ RH, at midnight $70 \pm 4 \%$, and at 8:00 AM $46 \pm 5 \%$ RH. The 2 nd night, humidity was $46 \pm 5 \%$ RH.

Five pairs of moths were observed each of 2 nights, from 8:00 PM to 11:00 PM at 15 min intervals, and continuously from 11:00 PM to 6:40 AM the 1st night, and from 11:00 PM to 5:20 AM the 2nd night. Thereafter, observations were made every 5-40 min until 8:06 AM the lst night and 6:45 AM the 2nd night. During breaks between the final observations, females were dissected for spermatophores and for observations of egg development and placement in the reproductive system. Males were dissected and the color of the 1st secretory area of the primary simplex recorded; these results are reported in the section above dealing with primary simplex and spermatophore color.

\section{Results and Discussion}

Until midnight the moths remained still or ran and/or flew about the cage with no seerning orientation to ecich other. If a fair met, they avoided each other by turning aside or dropping to the cage floor. Females were generally more active than males up to midnight, in contrast to daylight hours when the reverse is true, 
as seen in mating-oviposition cages in the culture room and in handling moths in other experiments.

In the description below, "calling" by females refers to a posiure in which the abdominal tip is thrust between and above the wings, and the ovipositor is intermittently protruded and retracted. "Whirring" by males refers to the wings raised vertically over the thoracic dorsum, and forming a blur describing arcs of an estimated $30^{\circ}$. At the same time, the abdomen is raised dorsally with the tip between the wings, except immediately before attempted coupling.

The female initiates pair formation by calling as she remains stationary on the horizontal lower surface of the cellucotton cage top or on the vertical cage side. The male begins vibrating his antennae up and down asynchronously, makes a circle in place, and approaches the female with his wings slightly parted. If the male approaches the female from behind, he flails her abdomen tip with his antennae, the female makes a half circle in place, and the moths flail each others' antennae head to head. If on the other hand the male approaches the female head to head, the moths flail each others' anterinae. The male then whirs his wings. The female may make no, 1, or several circles in place. The moths continue flailing each others' antennae if the female does not circle, or the male flails her body with his antennae if she circles. During this time the male continues bursts of whirring, separated by brief pauses. With the female facing the male, the male continuously whirs his wings as he curls his raised abdomen with claspers extended towards the female, quickly twists toward her right or left, and strikes at her abdomen tip. If coupling is successful, the male stops whirring and pivots in a half circle as the female pivots slightly placing the body axes in a straight line, end to end, flat to 
the surface. If the pair fails to couple, the female continues calling while the male pauses, the moths flail each others' antennae, and the male whirs continuously as he strikes again. This procedure is repeated 3-5 times until coupling occurs or the female walks away. After coupling and pivoting to the end-to-end position, the pair remains stationary and appressed to the surface.

Uncoupling begins with the mates gradually raising the abdomens to form a $130-140^{\circ}$ angle to each other. The male pumps his abdomen, finally raises his wings several times, and sometimes vibrates them briefly. The female may pump her abdomen as she grasps the surface. The pair may turn a half circle and back again while pulling alternately, or the male may turn about $40^{\circ}$ and then back again. The male abdomen may be bent into a vertical "S" shape during this process or remain straight but raised vertically. The mates ultimately uncouple either from a straight line position or at a $140^{\circ}$ angle to each other laterally.

After uncoupling, the mates tend to be active for 5-10 min moving abcut the cage and feeding, but finally settle down for the rest of the night.

Eight of the 10 pairs moted. Calling accurred from 1:15 AM to 6:40 AM the lst night, and from 1:45 AM until continuous observation was terminated (6:45 $A M$ ) the 2 nd night. Of 73 callings recorded, 19 initiated courtship, i.e., the attracted males whirred at least once next to the females. Of the 19 courtships, 7 led to coupling. In addition, 12 courtships occurred with females not observed calling immediately prior to courtship. However, half of these were in a single cage that was not observed as closely as the other cages, and calling could have occurred. In addition, courtship was sometimes initiated within minutes after calling began, and could easily be missed. Accepting these possibilities, apparently only calling 
females attract males.

In 4 matings, females called only once during the night, from $1 / 2$ to $5 \mathrm{~min}$, and were coupled within 1-7 $\mathrm{min}$ after initiating calling. Two other females calied intermittently over periods of 100 and $47 \mathrm{~min}$ in intervals lasting 2-54 min and 2-8 $\mathrm{min}$, respectively, before coupling. The lst was courted only once while the 2 nd was courted 4 times, once before she was observed calling during the night, and 3 times when she called.

The pair formation and courtship behavior of $\underline{E}$. lignosellus include activities suggestive of olfactory stimuli. Norris (1933) stated calling $\underline{P}$. interpunctella females stretch the intersegmental membrane bearing secretory tissue near the ductus bursae orifice. $\underline{P}$. interpunctella males become highly excited in the presence of calling females, but never become sexually excited in the presence of non-calling females (Norris, 1933; Barth, 1937). Dickens (1936) described scent scales arising from glandular areas on the 8th abdominal segment of $\underline{A}$. kuehniella, E. cautella, $\underline{E}$. elutella, and $\underline{P}$. interpunctella. Females of all 4 species had glandular intersegmental folds between the 8th and 9th segments. E. cautella females also have 2 internal odoriferous glands which open into the oviduct near the genital pore. Götz (1951) stated female calling in Lepidoptera exposes glands secreting sex pheromones. Evidence does not contradict that E. lignosellus males court and couple with females that are calling. Barth (1937) stated glands of $\underline{E}$. elutella males secrete an odorous substance that increases female excitement in copulation. Vibration of the wings disperses the odor. Courting E. lignosellus males whir with the abdomen tip, with claspers extended, held between the wings.

Coupling of $\underline{E}$. lignosellus occurred from 1:40 AM to $6: 40$ AM with 7 of the 8 
couplings occurring by 4:40 AM. Average time in copulo was 102 min (range 81134) including 5-10 $\mathrm{min}$ for uncoupling.

In unmated females, the membranous portions of the corpus bursae wall were pressed together and no visible fluid was present within the bursae. All mated females had a greenish fluid in the corpus bursae anterior to the spermatophore. Not more than 1 spermatophore was passed per mating.

Among mated females, 3 had full-sized eggs in the common and lateral oviducts, 4 had full-sized eggs in the lateral oviducts but not in the common oviduct, and 1 had only immature eggs, located in the ovarioles. The 2 unmated females had full-sized eggs in the lateral oviducts but not in the common oviduct. It appears $\underline{E}$. lignosellus females, like $\underline{P}$. interpunctella (Norris, 1932) mate without regard to egg development.

\section{Influence of Additional Females on Male Mating Frequency}

The presence of receptive moths was an important factor in mating studies. Mating cage sizes used by Luginbill and Ainslie (1917), Dupree (1965), Leuck (1966), Calvo (1966) and Stone were summarized in the preceding experiment. Mating occurred in all cages except 4-dr vials used by Stone. Pairs of moths mated in 40-dr vials, but to assure that receptive females were present for test males in other experiments, I decided that greater female numbers per cage might be desirable. The purpose of this experiment was to determine if additional females per male influenced mating frequency.

Materiols and Methods

Two-day-old males and females were caged in 40-dr vials for 1 day using 
the following numbers of individuals, male:females, with the space available per moth in each case: $1: 1,73.5 \mathrm{cc} ; 1: 2,49.0 \mathrm{cc} ; 1: 3,36.8 \mathrm{cc} ; 1: 4,25.4 \mathrm{cc}$. Equal numbers of each ratio were run on a given day until the ratios were replicated 100 times. At the end of each test, females were dissected for spcrmatophores.

\section{Results and Discussion}

Males mated with approximately equal frequency at all 4 ratios: 1:1, 60\%; $1: 2,61 \%, 1: 3,75 \% ; 1: 4,70 \%$. Chi square analysis indicated no significant differences at the $5 \%$ level. Either the lack of successful mating is principally attributable to the male or else additional females resulted in inhibiting factors approximately equal to the increased probability that at least 1 female would be receptive. Not more than 1 spermatophore was passed per night per male.

\section{Influence of Age on Mating}

There is much variation in the Lepidoptera as to age of mating. Richards and Thomson (1932) found that moths of the genera Ephestia and Plodia adults are ready to mate soon after emergence, almost as soon as the wings are dry. The corn earworm, $\underline{H}$. zea, never copulates the lst night after emergence or on the emergence night, and all copulations occur between the 2 nd and 7 th complete nights after emergence (Callahan, 1958a). The cabbage looper, Trichoplusia ni (Hübner), most frequently mates the 2 nd and $3 r d$ nights after emergence. Males never mate on the lst night after emergence, but a small percentage $(7 \%)$ of females mated the lst night (Shorey, 1964). However, Henneberry and Kishaba (1967) reported male cabbage loopers mated infrequently the lst night after emergence and most frequently the $3 \mathrm{rd}$ and 4 th nights after emergence. The pink 
bollworm, Pectinophora gossypiella (Saunders), mates most frequently at ages 5-6 days (Ouye et al., 1964). The oriental fruit moth, Grapholitha molesta (Busck), mates within $24 \mathrm{hr}$ of emergence, and males mate daily during the lst 7 days after emergence (Dustan, 1964). The granulate cutworm moth female, Feltia subterranea (F.), mates most frequently the 3rd night after eclosion (Cline, 1967).

The purpose of this experiment was to determine the influence of age on mating of 1-6-day-old lesser cornstalk borer males and females.

\section{Materials and Methods}

Moths $1-6$ days old were tested at 1 male: 4 females and vice versa for 1 day. All combinations of ages and both sex ratios were replicated 5 times each, making a total of 360 test cages. At the end of each test, females were dissected for spermatophores.

\section{Results and Discussion}

The data were pooled as indicated in Fig. 9. The overall average for the experiment was computed since mating frequency under the 4 conditions plotted in Fig. 9 was essentially the same (average 61\%, range 60-62\%). Mating frequency of each age group was compared with the overall average using a 2 -tailed " $t$ " test.

None of the 24 mating frequencies were significantly different from the overall average at the $1 \%$ level. Thus the lesser cornstalk borer mates equally well at age 1-6 days under the above conditions.

\section{Influence of Male Antennectomy on Mating}

Dethier (1953), Schneider (1964), and Jacobson (1965) include many references establishing the antennae of insects as the principal site of olfactory 

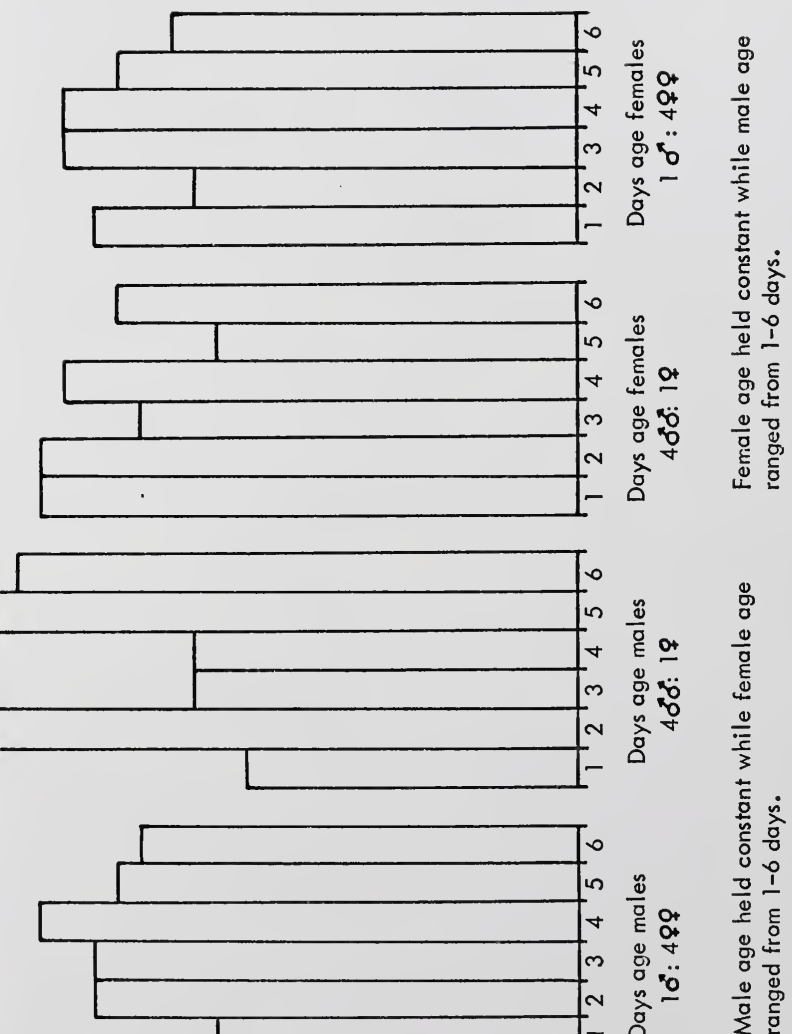

s
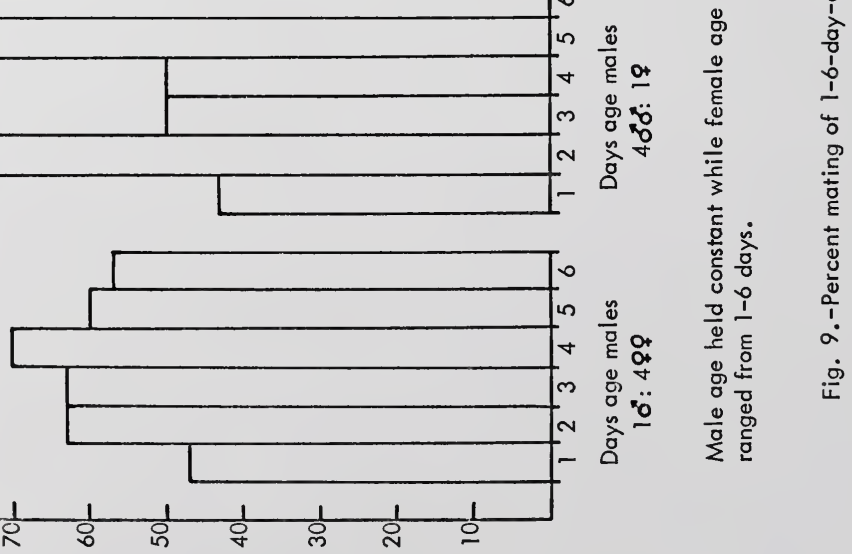

6u!tow \% 
receptors. This may explain why male moths deprived of their antennae or having antennae coated with various substances either do not mate or mate infrequently.

The purpose of this experiment was to determine the influence of bilateral antennectomy of the male on mating.

\section{Materials and Methods}

Two 2-day-old females were caged with two 2-day-old males handled in 1 of 3 ways. Group A males were caged untreated. Group B males were knocked down by a 5 sec exposure to $\mathrm{CO}_{2}$ and the left meso- and right metathorccic legs were excised between the thorax and the coxae. Group $C$ males were also knocked down with $\mathrm{CO}_{2}$ as in Group $\mathrm{B}$ and both antennae were excised between the head and the scape. All excisions were done with the aid of a microscope.

Groups were run concurrently and replicated 25 times. Cages were reicined 2 days.

\section{Results and Discussion}

In Group A, 47 spermatophores were passed, in Grcup B, 43, and in Group C, 1.

Complete bilateral antennectomy inhibits mating of $\mathrm{E}$. lignosellus males. Based on behavior of other Lepidopiera, this is possibly due to removal of olfactory receptors which írigger pair formation, courtship, and mating on reception of the female sex attractant.

\section{Longevity of Virgin and Mated Moths, Spermatophore Passage and Acceptance, and Fecundity}

The purpose of this research was to determine the longevity of virgin and mated moths, male and female mating frequency, the number of eggs laid per 
mated female, and the temporal oviposition pattern during the total oviposition period of mated females.

\section{Materials and Methods}

Twenty-five each virgin males and females were retained for life. Newly emerged moths were placed singly in 40-dr vials and assigned an identification number. Four to 8 moths of the same sex were caged as available on a given date. Males were caged on 5 days, every 3 rd day, and females were caged on 4 days, 2,6 , and 5 days apart.

Newly emerged moths used concurrently for longevity, mating frequency, and fecundity records were placed in 40-dr vials and assigned an identification number. Three 1- to 3-day-old virgin moths of the opposite sex were placed in each vial and were replaced daily for the life of the retained moths. As the retained moths died, they were replaced until 25 of each sex were tested. Dead retained mated females were dissected for spermatophores and retained eggs. A moth was considered dead when it failed to move appendages or pump the abdomen when gently proked. Females caged with single retained males were dissected for spermatophores when replaced by virgin females.

The research was conducted from January to March, 1967. On 10 February, cotton wads were replaced by cellucotton wads in the 40-dr vials, since older moths tended to entangle themselves in the cotton fibers. To statistically examine the influence of this change, using analysis of variance, all reiained mated moths dying prior to the change and exposed to no more than 6 days to cellucotton wads were assigned to group 1. Males with identification numbers 1-14 (excluoing male no. 11 which was exposed to cellucotton wads for 11 days) and females no. 1-6 
(excluding female no. 4 which was exposed to cotton wads for 7 days) were in group

1. All other moths were in group 2 except male no. 11 and female no. 4 .

Since nearly all virgin moths survived beyond 10 February, moths were assigned to groups based on the dates they were initiated in the experiment. Longevity, spermatophores passed or accepted, total, viable, and sterile eggs laid, number of eggs retained at death, length of oviposition period, and longevity alone were checked statistically using correlation coefficients for mated and virgin moths, respectively.

Eggs laid by retained mated females on the cellucotton tops, vial sides and bottoms, were set aside for $24 \mathrm{hr}$ before counting fertile ond sterile eggs. Fertile eggs turn from cream white to red, while sterile eggs remain cream colored or turn red at one end only.

\section{Results and Discussion}

Differences in longevity and fecundity when compared with other workers (Tables $5 \mathrm{cnd} 7$ ) may result from rearing history, summarized under rearing procedures above, methods of haridling adults, and genetic differences. Luginbill and Ainslie (1917), Dupree (1965), and Leuck (1966) rerained adults in unregulated rooms or outdoor screened insectaries, while Calvo (1966) maintained adults at consiant iemperatures and humidities. Sanchez (1960) worked with laboratory insects of unspecified conditions, except for a few observations discussed below. King et al. (1961) did not indicate what conditions were involved with his data. At the time of experimentation, my colony had passed thru 7 generations. Thus the genetic pool may have changed from that of the original stock that Calvo (1966) used and influenced the results. 
Table 5. -Longevity of lesser cornstalk borer adults.

\begin{tabular}{|c|c|c|c|c|c|c|}
\hline \multirow{2}{*}{$\begin{array}{l}\text { Reference } \\
\text { and State }\end{array}$} & \multirow[b]{2}{*}{ Sex } & \multirow{2}{*}{$\begin{array}{c}\text { Sample } \\
\text { Size }\end{array}$} & \multirow[b]{2}{*}{ Fed } & \multicolumn{3}{|c|}{ Days life } \\
\hline & & & & MeantSE & Range & Median \\
\hline \multirow[t]{4}{*}{ Stone. Fla. } & $m^{a}{ }^{0}$ & 25 & $2 \%$ sucrose & $24.2 \pm 1.5$ & $13-46$ & 24 \\
\hline & $v^{b}{ }_{0}$ & 25 & $"$ & $42.4+1.7$ & $25-64$ & 42 \\
\hline & $\mathrm{m} \%$ & 25 & $"$ & $18.1 \pm 1.7$ & $|2-3|$ & 17 \\
\hline & $\vee \&$ & 25 & $"$ & $37.6 \pm 1.8$ & $22-55$ & 35 \\
\hline Luginbill \& & $\delta$ & 7 & some fed sugar & $12.1 \pm 0.5$ & $7-18$ & 10 \\
\hline Ainslie. 1917. & & & sirup & & & \\
\hline Fla. \& S.C. & 우 & 7 & $"$ & $12.7 \pm 1.8$ & $5-18$ & 13 \\
\hline Sanchez. 1960. & $\delta$ & 12 & $?$ & $7.5 \pm 0.3$ & $4-12$ & 6.5 \\
\hline Texas & \& & 7 & ? & $7.1 \pm 0.5$ & $4-16$ & 6 \\
\hline King et al. & ర& \& 우 & $?$ & $?$ & 8 & $4-19$ & \\
\hline \multicolumn{7}{|l|}{ 1961. Texas } \\
\hline Dupree. 1965. & mò & $17^{c}(1957)$ & dilute honey \& & 11.4 & $2-23$ & \\
\hline \multirow[t]{3}{*}{ Ga. } & mồ & (1958) & sodium benzoate & 17.9 & $11-23$ & \\
\hline & $\mathrm{m}$ ? & $17^{c}(1957)$ & $"$ & 14.5 & $3-26$ & \\
\hline & $m$ ? & (1958) & $"$ & 19.5 & $7-33$ & \\
\hline Leuck. 1966. & vo & ? & $10 \%$ honey & $22.2 \pm 1.3$ & $3-29$ & \\
\hline \multirow[t]{2}{*}{ Ga. } & $m ?$ & $?$ & $"$ & $10.3 \pm 0.7$ & $4-16$ & \\
\hline & $\vee q$ & $?$ & $"$ & $21.4+3.6$ & $10-31$ & \\
\hline
\end{tabular}

mated

virgin

Dupree used at least 17 pairs in 1957-1958 combined. 
Longevity of individual mated males and females are shown in Figs. 10 and 11, respectively. Males exposed to cotton wads lived an average of 4.0 days shorter and females lived 2.5 days shorter than moths exposed to cellucotion wads. However, these differences were not statistically significant.

Mated males lived an average of 12.7 days (range 5-28) after passing the last spermatophcre (Fig. 10). Males no. 17 and 20 are not included in the average sirice male no. 17 may have died prematurely in copulo and male no. 20 failed to pass a spermatophore. Mated females lived an average of 4.7 days (range 1-13, median 4) after the last oviposition day. Virgin females lived roughiy twice as long as mated females, thus agreeing with Leuck's data (i966) (Table 5).

Callahan (1958a) concluded that once a corn earworm moth mates, it becomes less active than a virgin moth and hence lives longer on the average than a virgin. However, virgins held in holders for life lived longer than mated moths. He acknowledged his conclusion did not seem to hold for E. kuehniella (Zeller). The adulis do not ordinarily feed and virgins possibly iive longer by absorbing retained eggs.

Norris (1933) indicated that unfed virgin E. kueinniella females lived as long as mated females fed sugar solution. Perhaps virgin fernaies might live longer than mated females if fed, as was the case for $E_{0}$ lignosellus. Feeding versus starvation is probably the decisive factor in E. lignosellus longevity, not degrees of activity at least in males, as seen in 29 deaths of mated unfed males in the mating cage conditions experiment versus no deaths of mated fed males.

Spermatophore passage and acceptance results are shown and compared with other species in Table 6. Figures 10 and 11 show spermatophore passage patterns. 
Table 6.-Spermatophore passage and acceptance during the lifetime of various Lepidoptera

\begin{tabular}{|c|c|c|c|c|c|}
\hline Reference & $\begin{array}{l}\text { Scientific and } \\
\text { common name }\end{array}$ & Sex & $\begin{array}{c}\text { Mean } \\
\pm S E \\
\end{array}$ & Range & $\begin{array}{c}\text { Individuals } \\
\text { per mating } \\
\text { cage } \\
\delta 0^{\circ}: \$ \%\end{array}$ \\
\hline Shorey e! al. & Trichoplusia ni & \& & 2.0 & $0-6$ & $?$ \\
\hline 1962. & Cabbage looper & & & & \\
\hline Shorey. 1964. & $"$ & 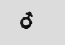 & 2.0 & $0-10$ & $1: 2$ \\
\hline \multirow[t]{2}{*}{ Dustan. 1964.} & Grapholitha molesta & ? & 1.5 & $1-4$ & $20: 20 \&$ \\
\hline & Oriental fruit moth & & & & $25: 25$ \\
\hline Ouye et al. & Pectincphora gossypiella & o & 4.2 & $0-10$ & $1: 3^{a}$ \\
\hline 1965. & Pink boolworm & ㅇ & 2.3 & $0-8$ & $6: 1^{a b}$ \\
\hline \multirow[t]{2}{*}{ Cline. 1967.} & Feltia subterranea & $\sigma^{*}$ & 4.9 & $0-8$ & $1: 3$ \\
\hline & Granulate cutworm moth & & & & \\
\hline Henneberry \& & Trichoplusia ni & ㅇ & $1.2-1.4$ & $?$ & $3: 3$ \\
\hline Kishaba. 1967. ${ }^{\mathrm{C}}$ & & & & & \\
\hline \multirow[t]{2}{*}{ Hughes. 1967.} & Phthorimaea operculella & oे & $4.2+0.3$ & $1-10$ & $1: 2$ \\
\hline & Potato tuber moth & \& & $2.6+0.2$ & $1-6$ & $2: 1$ \\
\hline \multirow[t]{2}{*}{ Stone } & Elasmopalpus lignosellus & o & $7.2+0.8$ & $0-14$ & $1: 3$ \\
\hline & Lesser cornstalk borer & \& & $1.7+0.2$ & $1-3$ & $3: 1$ \\
\hline
\end{tabular}

a Three virgin moths age 2-5 days, and virgins no more than 2 days old replacing dead moths, were added every 3-4 days for life of test moths.

b When 75:25 ơ :

c The authors were checking temperature effects concurrently. 


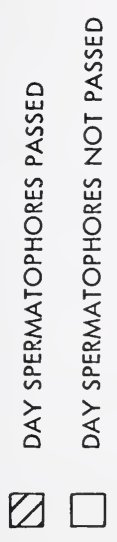



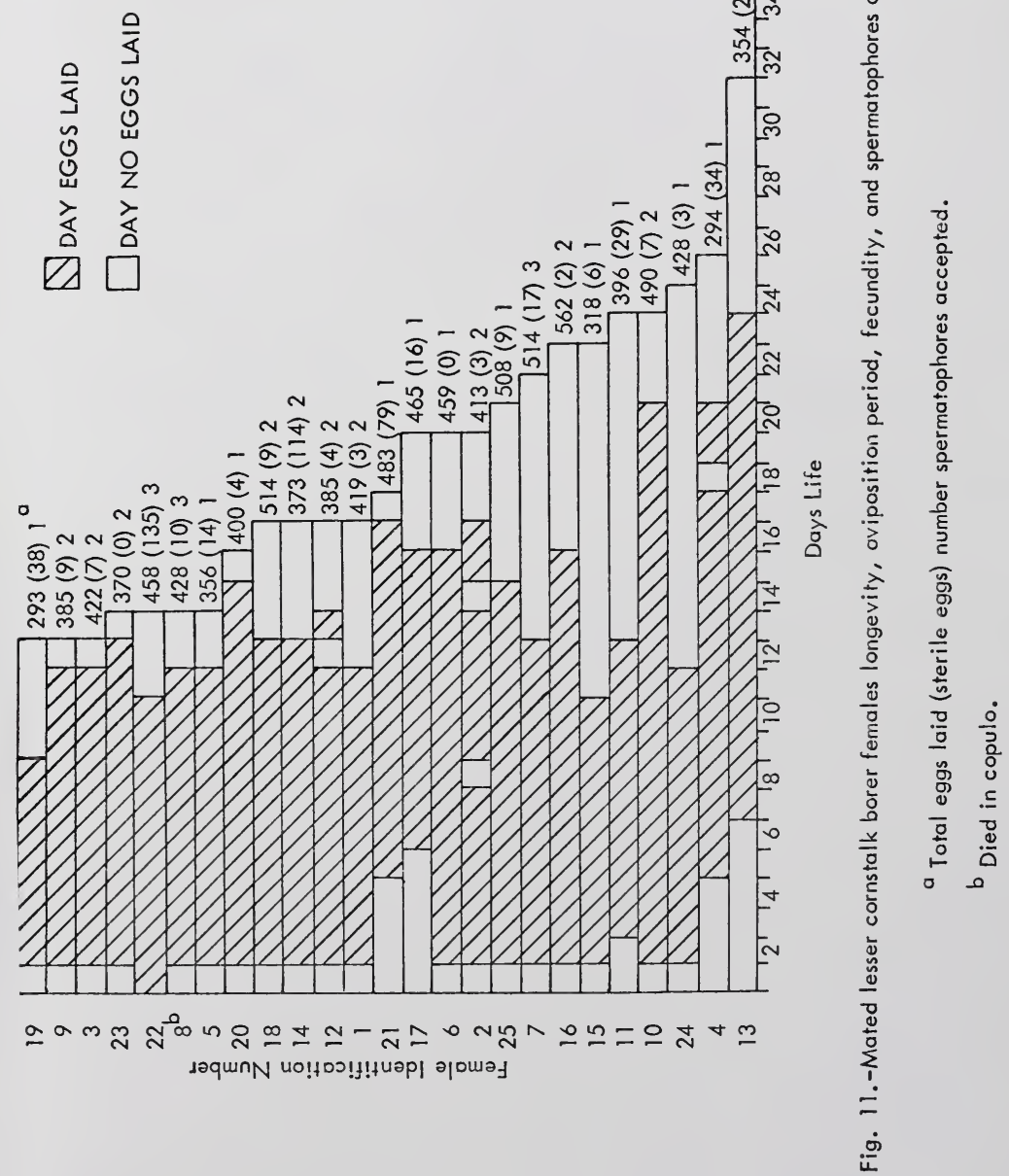
Figure 12 indicates the total number of spermatophores passed by 25 males per day.

Mated males dying prior to replacement of cotton wads with cellucotton wads passed an average of 3 spermatophores fewer than males after replacement, but the difference was not statistically significant.

No more than 1 spermatophore was passed per day per male except for male no. 16 which passed 1 spermatophore to each of 2 females the lst day of caging.

Authors included in Table 6 used various methods to determine spernatophore passage and acceptance during math life span. Shorey (1964), Cline (1967), Hughes (1967), and Stone replaced virgins of the opposite sex daily for life of test moths. Shorey et al. (1962), Dustan (1964), and Henneberry and Kishaba (1967) caged moths at various ratios for life of females with no daily replacement of virgin males. Ouye et al. (1965) initiated studies with 3 virgin females per male and 6 virgin males per female to determine poiential mating frequency of males and females caged for life. Three more virgins were added every 3-4 days during the test moths' lives, and dead moths were replaced by virgins to assure receptive maths of the opposite sex were present.

The average reproductive life of $\underline{E}$. lignosellus males, counting from day 1 to the day the last spermatophore was passed (male no. 20 was not included since it passed no spermatophore) was 10.2 days (range 3-18, median 11) (Fig. 10). Within 3 days, all males except male no. 20 had mated at least once. In 5 days $49 \%$ of all spermatcphores were passed, in 14 days $99 \%$ (Fis. 12).

The lesser cornstalk borer showed no significant correlation berween male mating frequency (spermatophores passed) and longevity. In contrast, Shorey (1964) reported the principal factor limiting copulation frequency of T. ni males was longevity. 


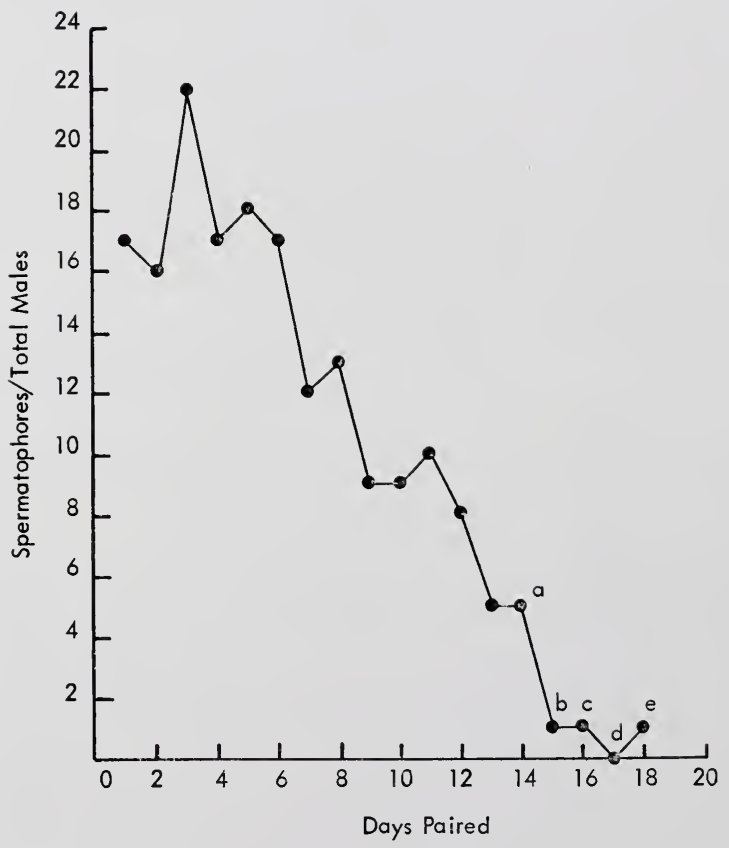

Fig. 12. -Total number of spermatophares passed per day by 25 lesser cornstalk borer males, number of males after day 13 as indicated
a 24 live males in sample
b 23
c 22
d 21
e 20 
Shorey (1964) speculated the female may be the limiting partner, determining the average mating frequency in a population having an equal sex ratio. The lesser cornstalk borer female is the limiting partner, since males passed an averoge of $7.2 \pm 0.8$ spermatophores during a lifetime when caged claily with 3 virgin femoles, while females accepted only $1.7 \pm 0.2$ spermatophore under comparable conditions.

Male no. 17 and female no. 8 remained continuously coupled to mates for 3 nights and 2 days before dying. In contrast, male no. 25 coupled on day 5 and remained coupled with 1 female until day 6 , when it unccupled and mated with another female. On day 7 , it coupled again with 1 female thru day 8 when it uncoupled. The observations indicated an $\underline{E}$. lignosellus male can disengage after prolonged coupling. Shorey (1964) and Callahan and Chapin (1960) reported that I. ni and $\underline{H}$. zea remaining coupled during the day were unable to disengage and died coupled. Hughes (1967) mentioned mating pairs of $\underline{P}$. operculella unable to separate. Lugiribill and Ainslie (1917) reported a caged pair of lesser cornstalk borer moths found in copulo unable to uncouple.

Dissections of prolonged coupled moths, in this experiment and in matingoviposition cages used in colony maintanence, showed the cornutus, the chitinous tocth on the everted endophalus, was inserted into the bursa copulatrix and bent at a right angle to the endophalus where it entered the bursa, thus preventing retraction of the endophalus thru the ductus copulatrix. In some cases, a malformed spermatophore collum and corpus entangled the endophalus and cornutus within the bursa and ductus copulatrix.

Table 7 compares fecundity results with those of other workers. Fig. 13 
Table 7.--Fecundity of the lesser cornstalk borer

\begin{tabular}{lccr}
$\begin{array}{l}\text { References } \\
\text { and states }\end{array}$ & $\begin{array}{c}\text { Sample } \\
\text { size (\%o) }\end{array}$ & Mean \pm SEgs loid/female \\
\hline Stone. Fla. & 25 & $419.5 \pm 14.7$ & $293-562$ \\
Luginbill \& Ainslie. & 6 & 192 & $91-342$
\end{tabular}

1917. Fla. \& S.C.

King et al. 1961.

?

124

Texas.

Dupree. 1965.

$17^{a}(1957)$

128.9

$11-261$

Ga.

$17^{a}(1958)$

61

5-221

Leuck. 1966.

?

$125.7 \pm 20.5$

2-314

Ga.

Calvo. 1966.

35

67

Fla.

a Dupree used 1797 in 1957-1958 combined. 
illustrates the average number and standard error of eggs laid per day. No significant correlations were found among longevity, spermatophores accepted, total eggs laid, sterile eggs laid, and length of oviposition period. Correlation between number of eggs laid and the number of fertile eggs was significant at the $1 \%$ level $(r=.8089)$.

Callahan (1958a) and Shorey (1963) found no correlation between longevity

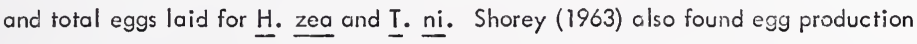
increased as numbers of spermatophores increased for females laying viable eggs, but percent viability was not markedly correlated with mating frequer:ey.

In the discussion below, day refers to time of poiring, but ovipcsition day refers to a day counting from the 1st day eggs were laid by a particular female or by females. Once eggs are laid, even days without additional egg laying are counted as "oviposition days" within the oviposition period. This happened only 4 times (Fig. 11).

Of the eggs laid by 25 females, $56 \%$ were laid by the 4 th oviposition day, or $48 \%$ by the 4 th day.

The average oviposition period for 25 females, counting from the lst through the last oviposition day was 11.8 oviposition days (range $7-19$, median 10) or 14.6 days (range 8-23, median 12) counting from the lst day of caging through the last oviposition day. Females delaying oviposition no more than 1 day averaged 11.5 ovipcsition days (range 7-19), while 5 females delaying oviposition more than 1 day averaged 13.0 oviposition days (range 10-17). Dupree (1965) found that the oviposition period was 7.8 days (range 1-18) 1 year and 4.1 days (range 1-9) the following year. Luginbill and Ainslie (1917) recorded 5 females 


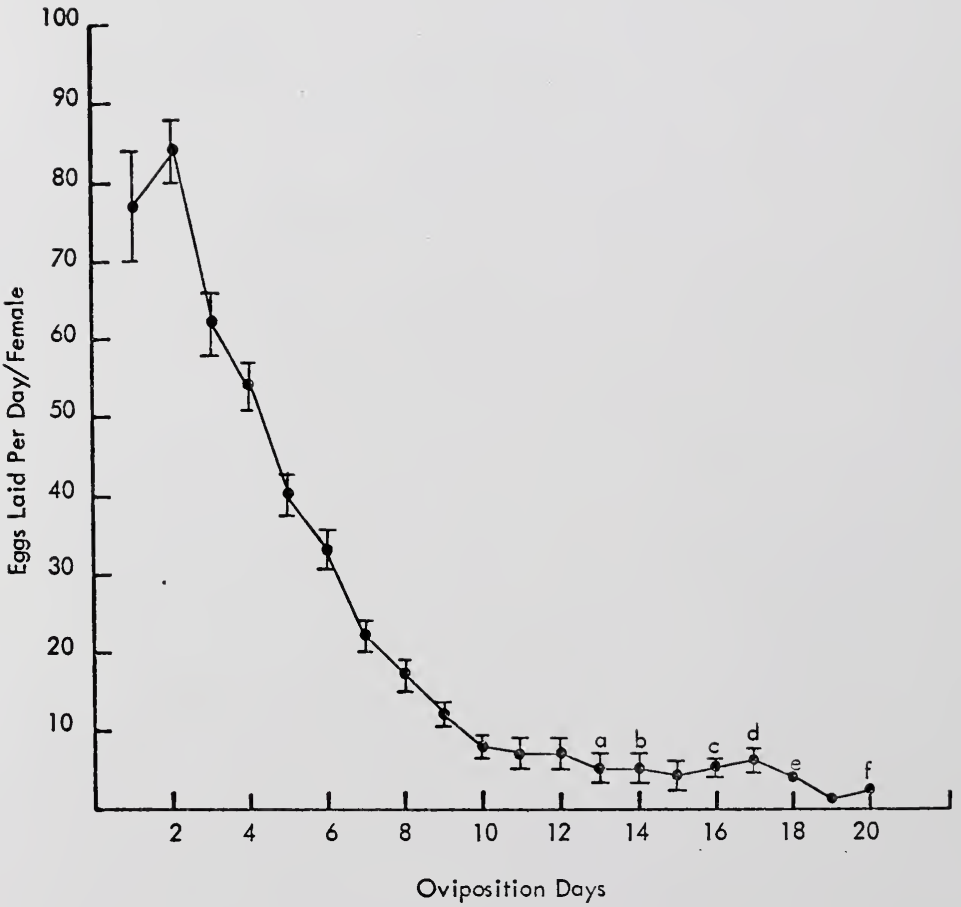

Fig. 13. - Average numbers of eggs laid per day by 25 lesser cornstalk borer females, number of females after day 12 as indicated. Standard errors shown with horizontal lines
- 22 live females in sample
b
18
c 17
d 13
e 12
f 9 
oviposited an average of 10.4 oviposition days (range 7-14).

Leuck (1966) stated that caged females oviposited nightly all their lives, but females in the work reported here lived an average of 4.7 days (range 1-13, median 4) after the last oviposition day. Dupree (1965) stated oviposition usually occurred on alternating days, rarely on consecutive days. Only female no. 2 laid larger egg numbers every other day thru day 9, with differences of 50-70 eggs on successive days. Perhaps Dupree's moths reflected temperature effects in the outdoor inseciary, as he mentioned the average minimum and maxirnum temperatures during experimentation were 66.6 and $86.4^{\circ} \mathrm{F}$ in 1957 and 66.8 and $88.2^{\circ} \mathrm{F}$ in 1958. Lugiribill and Ainslie (1917) stated oviposition did not occur when the remperature "fell much blow $80^{\circ} \mathrm{F}$," but did not state clearly under what condition moths were kept. Sanchez $(1960)$ stated field collected adults maintained at $65^{\circ} \mathrm{F}$ continued ovipositing, but adults kept at $35^{\circ} \mathrm{F}$ were inactive. However, he did not study oviposition patterns. Perhaps these discrepancies in responses to temperature reflect differing genetic strains.

The variation in numbers of eggs laid on oviposition day 1 (range 2-135, median 86) might result from varying times of mating and/or varying rates of sperm passage from the bursa copulatrix to the receptaculum seminis.

Table 3 summarizes variations from basic oviposition patterns, and includes only females showing at least 2 of the variations listed. All females laying more than the average percent sterile eggs of total eggs laid are included (population average $5.5 \%$, Iange $0-30.4 \%$ ). Four of 5 females delaying oviposition more than ? day, 5 of 8 females retaining more than 10 eggs (population average 8.7 , range $1-26)$, and 3 of 7 females ovipositing in daily numbers differing from the usual 
Table 8. - Lesser cornstalk borer females showing 2 or more variations from basic population oviposition patterns.

\begin{tabular}{ccccc}
$\begin{array}{c}\text { Female } \\
\text { no. }\end{array}$ & $\begin{array}{c}\text { Ave. \% } \\
\text { sterile eggs }\end{array}$ & $\begin{array}{c}\text { Delayed ovipo- } \\
\text { sition (days) }\end{array}$ & $\begin{array}{c}\text { Retained } 10 \\
\text { eggs at death }\end{array}$ & $\begin{array}{c}\text { Irregular daily } \\
\text { oviposition pattern }\end{array}$ \\
\hline 14 & $30 \%$ & - & - & + \\
22 & $29 \%$ & - & 15 & - \\
21 & $16 \%$ & 5 & - & - \\
19 & $13 \%$ & - & 11 & + \\
4 & $12 \%$ & 5 & 26 & + \\
11 & $8 \%$ & 3 & 19 & - \\
13 & $7 \%$ & 7 & 21 & + \\
\hline
\end{tabular}

a Laid 2 fertile eggs on day 1. 
daily decreasing pattern (Fig. 13) are included. Only females no. 21 and 22 laid more than the average total number of eggs. Females no. 4 and 19 represent the 2 lowest fecundity records obtained.

The data indicate females laying more than the average percent sterile eggs of all eggs laid tend to show other variations. Seven females not included in Table 8 showed only 1 variation of the 4 listed.

Nineteen females began ovipositing on day 2. Female no. 22 laid eggs the lst day of caging, while 5 females delayed oviposition more than 1 day (Fig. 11). A. kuehniella females underwent periods of quiescence after mating, usually 12 to $24 \mathrm{hr}$. During this time the sperm passed from the bursa copulatrix to the receptaculum seminis. Then oviposition began, lasting to within the last day or 2 of life (Norris, 1933). If this is the case in E. lignosellus, then one could assume the 19 females probably mated on day 1 and were ready to oviposit on day 2 . Female no. 22 must have mated on day 1 , as the 2 eggs laid were fertile. The 5 females delaying oviposition may have mated the day before they initiated oviposition or perhaps they indicated a wide range of sperm passage rate from the bursa to the glandula receptaculum.

Thirteen females laid decreasing numbers of eggs from oviposition day 1 , disregarding increases of less than 10 eggs in production on 2 successive days. If oviposition day 1 is disregarded due to the variation in egg numbers laid, then 18 females laid decreasing numbers of eggs daily. Norris (1933) found A. kuehniella females laid the greatest number of eggs during the 1st 2 days and then decreased production gradually until the last day or 2 of life, when 1, 2, or no eggs were laid. This agrees with lesser cornstalk borer egg production, except that $\underline{E}$. 
lignosellus females live longer on the average after the last oviposition day.

Of females differing from the daily decreasing oviposition pattern, 1 tended to oviposit on alternate days (female no, 2 discussed above), 1 reached peak production on oviposition day 3 , and another on oviposition day 4 . Four females reached a $2 \mathrm{nd}$ peak production (at least 15 more eggs laid' than on the previous oviposition day) after the lst 2 oviposition days -- 2 on oviposition day 4,1 on 5 , and 1 on 6 .

A. kuehniella females laid sterile eggs at any point in life (Norris, 1933). All gradations in fertilization reduction occurred and oviposition of no viable eggs was associated with the absence of sperm from the receptaculum seminis of mated females or with the presence of small quantities of sperm, much smaller than in normally mated females. When spermatozoa were present, they were less violently motile than usual, and in some cases they were motionless, perhaps due to retarded spermatogenesis, which also might cause the male to pass reduced quantities of sperm. Altho the above factors were not checked in my research, they might have influenced sterile egg production.

Twenty-two females laid less than $10 \%$ sterile eggs of all eggs laid on oviposition day 1 . The 3 females laying more than $10 \%$ laid 20,49 , and $66 \%$. Two females laid sterile eggs every oviposition day (females no. 21 and 22), while 2 females laid no sterile eggs during the entire oviposition period (females no. 6 and 23).

Concerning spermatophores accepted by females listed in Table 8, 4 females delaying oviposition accepted 1 spermatophore each. A 5th moth delaying oviposition accepted 2 and oviposited in a daily pattern of decreasing numbers of 
eygs as shown in Fig. 13. Assuming no parthenogenesis occuired, all 5 females mated on or by oviposition day 1 , since each laid some fertile eggs on oviposition day 1. The other 3 females in Table 8 accepted 1, 2, and 3 spermatophores (females no. 19, 14, and 22, respectively). Females no. 4, 11, 19, and 21 tended to lay iricreasing perceniages of sterile eggs daily as fewer eggs were laid. Perhaps the sperm supply was becoming exhausted with time.

The 3 of 25 females accepting 3 spermatophores retained 14-19 eggs at death. Five other femiales (Table 8) (4 accepted 1 spermatophore, 1 accepted 2) retained more than 10 eggs at death. Correlation between the number of spermatophores accepted and the number of eggs retained at death was significant at the $5 \%$ but not at the $1 \%$ level $(r=.5006)$.

Of females ovipositing daily eggs numbers varying from the basic curve (Fig. 13), 3 females accepted 1 spermatophore and 4 females accepted 2.

No record was kept of how many eggs were laid by virgin females retained for life, nor were the eggs retained for hatch. However, other workers have not reported that parthenogenesis occurs among the Phycitidae.

\section{Time of Oviposition}

Few workers have reported the time of oviposition of the lesser cornstalk borer. Luginbill and Ainslie (1917) stated that oviposition of caged females began shortly after dusk and continued until the early morning hours. The majority of eggs were laid during the forepart of the night. No eggs were laid diurnally or in bright light at night. Leuck (1966) reported that caged females oriposited shortly after dark and throughout the night. 
Materials and Methods

Paper sheets were placed on screen tops of 3 mating-oviposition cages as described under rearing techniques. The sheets were replaced every $4 \mathrm{hr}$ starting at 3 PM 1 day and ending at 7 PM the following day. To determine if oviposition occurred during the hour before the lights turned off (at 8 PM), sheets were left on the cages from 7-8 PM at the end of the experiment. All sheets were set aside for at least $30 \mathrm{hr}$. The eggs were then counted with the aid of a microscope.

\section{Results and Discussion}

All 3 populations oviposited over $90 \%$ of all eggs laid from $7-11$ PM (92, $95,98 \%)$. From 11 PM to 3 AM, the 3 populatiors oviposited 8,3 , and $2 \%$ of all eggs laid, respectively. The remaining eggs were laid between $3 A M$ and 7 AM, except for 1 sterile egg laid between 7-8 PM on the 2 nd day. Thus moths oviposit primarily during the $1 \mathrm{~s}+3 \mathrm{hr}$ of total darkness.

\section{Response of Adul ts to Sound}

Sound reception by moths has attracted considerable attention in recent years. The tympanic organs of noctuid moths are sensitive to sounds ranging from 3-240 kc/sec with maximum sensitivity between $15-60 \mathrm{kc} / \mathrm{sec}$ (Roeder and Treat, 1957). Tympanic nerve preparations detect bat cries at a distance of $30 \mathrm{~m}$ or more (Roeder and Treat, 1960).

Insectivorous bats use ultrasonic cries to echolocate night flying insects (Griffin, 1953; Griffin and Novick, 1955; Novick, 1965). Roeder and Treat (1960) found that many free flying moths perform evasive behavior in the presence of bats. The same is true when moths are subjected to an artificial 
approximation of bat cries (Rceder, 1962; Agee, 1967). The intensity of the sound stimulus is directly related to the type of moth response (Roeder, 1964); diving responses are most prevalant around 75-85 db, while turning-away responses are most prevalant around 45-55 db. No evidence indicates tympanate moths can distinguish differences in sound frequency (Roeder, 1966). It was concluded that the evasive behavior had a selective advantage and that probably the major function of moth tympanic organs was to warn night flying moths of approaching bats (Roeder and Treat, 1960).

Several workers examined practical application of moth respense to sound. Belton and Kempster (1962) broadcast ul trasonic sound at $50 \mathrm{kHz}$ and obtained more than $50 \%$ reduction of sweet corn infestation by the Eurcpean corn borer, Ostrinia nubilalis (Hübner). Treat (1962) captured more than twice as many tympanate moths in silent light traps than in light traps broadcasting recorded ultrasonic bat cries. Agee (1967) attempted to reduce oviposition of bollworm moths, H. zea, and tobacco budworm moths, Heliothis virescens (F.), in cotton fields with ultrasonic sound. He felt the negative results obtained were due to equipment failure during the moths' most active periods. Payne and Shorey (1968) found that pulsed ultrasonic sounds, especially at high intensities, reduced oviposition by the cabbage looper moth, I. ni, on lettuce and broccoli crops. The tympanic organs might have other auditory or proprioceptive functions unconcerned with bat detection (Trect, 1955), such as echo-location (Roeder and Treat, 1957). However, Treat (1955) suggested diuina! Lepidoptera possessing tympanic organs might have recently acquired the diurnal hobit, and the organs have persistea without survival value. On the other hand, perhaps the diurnal 
fliers also fly at night when an auditory sense might be of more benefit. He mentioned the typically diurnal butterflies have a poorly developed auditory sense, if it exists at all.

Roeder and Treat (1960) inferred that most moths with known auditory organs are medium sized (10-40 $\mathrm{mm}$ wing span). Few of these moths escaped attack by bats but many escaped capture.

In addition to the tympanic organs, Lepidoptera have several other organs or structures which may assist in sound perception (Haskell, 1961). These include: (A) Johnston's organ in the 2nd antennal segment; (B) the subgenual organs, generally found in the proximal region of the tibiae of all legs; (C) chordotonal sensillia, scattered about the body; and (D) hair sensillae, scattered over the body but especially on the thorax and abdomen. All of these structures respond to 10 $\mathrm{kc} / \mathrm{sec}$ or less so far as is known among the Insecta, but little research has been done with the Lepidoptera. Functions attributed to the tympanic organs might in fact be carried out by the above structures in combination with each other and/or with the tympanic organs, since no one has reported bat avoidance by deafened moths.

Further, adult Lepidoptera themselves produce sound by various means, but little is known about their behavioral significance (Haskell, 1961; Alexander, 1967). Haskell (1961) catagorized the principal types of sound producing mechanisms into 2 groups. The 1st group includes sounds produced by products of some usual moth activity, as the ultrasonic sound of $15 \mathrm{kc} / \mathrm{sec}$ and possibly higher produced in the flight of Prodenia eridania. Roeder and Treat (1957) suggested the sound might be associated with precopulatory behavior. Shorey (1964) found that 
bilateral iympanectomy of both sexes of I. ni possibly reduced but did not prevent successful copulation.

The 2nd major group includes several mechanisms such as frictional mechanisms, vibiating membranes, and mechanisms directly involving air movement (Haskell, 1961). These mechanisms include: (A) scraping raised fore and hind wing veins together producing frequencies up to $14 \mathrm{kc} / \mathrm{sec}$, as in the Peacock Butterfly (Nymphalis io); (B) rubbing wing ridges with some part of the leg, as in many noctuid moths; (C) clicking of wing membranes which pop in and cut when the wings are knocked together, as in Hecatesia; (D) rubbing a ribbed and a pegged wall of an abdominal cavity together, as in certain Lymantriid male moths; (E) forcing air thru the proboscis by means of pharynx pumping with the epipharynx interrupting air flow, as in Acherontia atropos; and (F) possibly forcing air thru spiracles, as in Arctia caja.

Perhaps some of the above mechanisms include clues to cornmunication between the sexes involving sound perception by the tymparic organs, but as Alexander (1967) indicates, this possibility has scarcely been investigated. In addition, the tympanic organis sense natural sounds other than bat cries, as rustling leaves and cricket chirps. Other functions could be served by the fympanic organs opart from bat detection, but no evidence of the importance of such perception is available as yet (Roeder and Treat, 1961a, 1961b).

The purpose of this experiment was to determine if E. lignosellus adults respond to sonic and ulírasonic sound.

\section{Materials and Methods}

A cylindrical cage of fiber glass screen and clear plastic, $6.5 \mathrm{~cm}$ high $\times 2.5$ 
$\mathrm{cm}$ diam, was used to cage individual test moths. The cage top and bottom perimeters were plastic rings $1.5 \mathrm{~cm}$ and $0.5 \mathrm{~cm}$ wide, respectively. The screen was sewn together along the side with thread and gived to the 2 rings. A small piece of fitted fiber glass screen formed the bottom. The cage with a moth was inverted into a small plastic dish with a fitted cellucotton disk saturated with $2 \%$ sucrose solution.

Preliminary tests indicated $66-100 \%$ of moths tested nocturnally (10:30 PM: to $1: 30 \mathrm{AM}$ ) at $3-16 \mathrm{kHz}$ with $3.3-20$ volts of amplitude remained quiet throughout the tests. Other moths moved about the cage and/or stroked their antennae, while still others extended their abdomens with tone bursts and contracted the abdomens to the normal position during silence after a tone burst. This latter activity was used as the criteria for a positive response in the following tests since it was repeatable at $20-60 \mathrm{kHz}$.

Five each 2-day-old males and females were tested for behavioral response from 2-4 PM and another set of 5 males and 5 females of the same age from 9:4511:00 PM. The cage was set $46 \mathrm{~cm}$ directly in front of a Dukane lonovac $\$$ Duk-5 speaker with a power supply modified for extended frequency response. Pure tones from $20-60 \mathrm{kHz}$ in $10 \mathrm{kHz}$ increments were produced with a Hewiett-Packard oudio oscillator model $200 \mathrm{CD}$. Three $1 / 2 \mathrm{sec}$ tone bursts were separated by 4 sec using a General Radio ${ }^{\circledR}$ tone burst generator type 1396-A timed by a HewlettPackara ${ }^{(}$audio oscillator model 201 C. At least 10 sec separated a tone burst triplet from the next.

Voltages of amplitude scale settings were determined with an oscilloscope as: 20 scale setting $=1.1$ volts; $30=1.9$ volts; $40=3.3$ volts; $50=6.4$ volts; $60=$ 


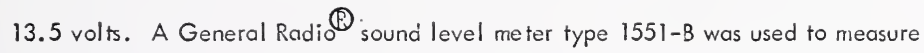
intensity on the A scale a: $46 \mathrm{~cm}$ from the speaker. At $10 \mathrm{kHz}$, the following amplifude sca!e settings were recorded in decibells: $10=54 \mathrm{db} ; 20=61 \mathrm{db} ; 30=$ $66 \mathrm{db} ; 40=71 \mathrm{db} ; 50=76 \mathrm{db} ; 60=80 \mathrm{db}$. These sound levels correspond to the above voltages. The loncvac tweeter was found to be linear within $\pm 2.5 \mathrm{db}$ between 10 and $60 \mathrm{kHz}$. Consequently the voltage readings should be convertible to scund levels with the same scale for all frequencies.

Moths were subjected to various frequencies and amplitudes. In the lst test, frequencies were he!d constant in the following order: $40,30,50$, and $40 \mathrm{kHz}$. In each frequency test, amplitude dial settings were varied in the following order: $60,40,20,30$, and 50 .

In the 2 nd test, amplitude was held constant at full setting (20 volts) as frequency was varied in the following order: $20,30,40,50,60,40,20,30,50$, and $60 \mathrm{kHz}$.

The cage was lighted with about $23 \mathrm{ft}$-candles during the afterrioon tests. During the evening tests, a $71 / 2$ watt red light $7.5 \mathrm{~cm}$ distant illuminated the cage with about 2-3 ft-candles. The room temperature was $27 \pm 1^{\circ} \mathrm{C}$.

\section{Results and Discussion}

In general, moths responded to high and low frequencies at high amplitudes (Fig. 14). Females responded essentially the same during day and night, but males were more responsive at night.

The test af bilateral tympanectomy on sound response was attempted but abandoned due to moth size and delicacy and the tympanic organ position. The wings, thorax and/or abdomen were usually damaged during the operation. Unlike 
noctuid tympanic organs, those of E. lignosellus are located on the lst abdominal segment and are covered by the metathoracic coxae. In addition, a fan of elongated scales originating on the abdominal pedicel obscures the tympanal surface. The operation was performed by anesthetizing a moth with $\mathrm{CO}_{2}$, placing it on its back, pressing with a pin on the sclerotized rim surrounding the tympanic organs, and thrusting the pin point dorsally and posteriorly simultaneously. The operation was essentially done in the blind. Often the tympanic membrane and scolopophorous organ were still intact in moths checked later to determine operutional success.

E. lignosellus is responsive to sound, but whether this is due to reception by the tympanic organs was not determined. The function of the tympanic organs in E. lignosellus is unknown. 


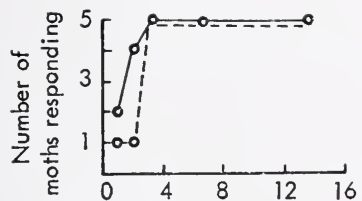

Amplitude (volts) $30 \mathrm{kHz}$

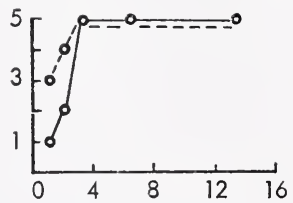

Amplitude (volts) $40 \mathrm{kHz}$

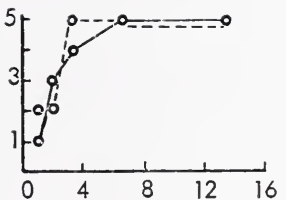

Amplitude (volts) $50 \mathrm{kHz}$

Diurnal response

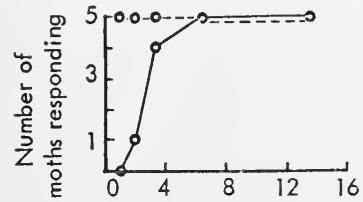

Amplitude (volts) $30 \mathrm{kHz}$

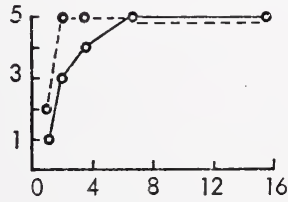

Amplitude (volts) $40 \mathrm{kHz}$

Nocturnal response

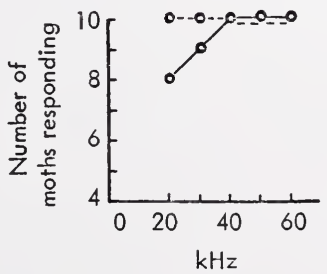

Amplitude 20 volts

Diurnal and nocturna!

response combined

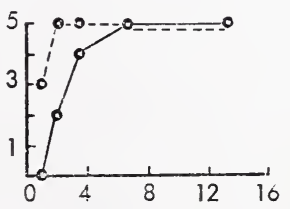

Amplitude (volts) $50 \mathrm{kHz}$

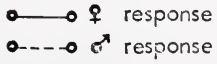

Fig. 14.-Diurnal and nocturnal response of lesser cornstalk borer adults to various amplitudes and frequencies. 


\section{SUMMARY}

Need for basic research on the reproductive biology of the lesser cornstalk borer, Elasmopalpus lignosellus (Zeller) (Lepidoptera: Phycitidae) prompted this research. The borer reportedly attacks 62 host plants representing 14 plant families, but host records may be incorrect due to similar feeding habits of other species.

A rearing technique was developed. Sixty to 80 pupae were obtained per 100 eggs. Total time from egg to adult was 24-28 days. The colony was reared for 34 months or approximately 32 generations. Ninety-five percent of pupae obtained were normally formed. Lightly sclerotized aberrations occurred on the venter of $5 \%$ of pupae obtained. Approximately $92 \%$ and $78 \%$ emergence of normal adults was obtained from normal and aberrant pupae respectively.

The male and female reproductive systems, including spermatophore morphology and position in the bursa, were studied and compared with other Lepidoptera. Colorless fluid in the lst secretory area of the primary simplex of the male indicated a mating (=spermatophore transfer) less than $24 \mathrm{hr}$ previously. Virgin 1-6-day-old males had translucent yellow simplex fluid, and males that mated 2-5 days previously had transparent yellow simplex fluid. Within $24 \mathrm{hr}$ after mating, simplex fluid in 3-day-old mated males changed from transparent colorless to transparent yellow. Color of spermatophores representing 3 successive matings was clear transparent. Thus lst matings were indistinguishable from subsequent matings on the 
basis of spermatophore color. Females had no full-sized eggs at emergence, but might have them present in the calyx, lateral oviducts, and/or common oviduct as well as in the ovarioles within 1-2 days after emergence.

The abdominal tympanic organs were studied and compared with the general pyraloid description. The tympani were ventrally and anteriorly located on the lst abdominal segment.

Mating occurred in $40-d r$ vials but not in 4-dr vials. In the $40-d r$ vials no significant differences in mating success occurred in respect to cage position, cage top materials, and fed versus unfed moths for a single mating per pair. Fed moths were more likely to mate again than unfed moths.

Mating behavior was observed, including pair formation, courtship, time of coupling, duration of copulation, uncoupling of mates, and post copulatory activity. Pair formation and courtship behavior included activities suggestive of olfactory stimuli. Mating occurred from 1:40 AM to 6:40 AM. Males mated with approximately equal frequency when caged for 1 day with $1,2,3$, or 4 females. One- to 6-doy-old moths mated equally well. Complete bilateral antennectomy of males inhibited mating.

Virgin males lived $42.4 \pm 1.7$ days (mean \pm standard error), mated males 24.2 \pm 1.5 days, virgin females $37.6 \pm 1.8$ days, and mated females $18.1 \pm 1.7$ days. Males passed $7.2 \pm 0.8$ spermatophores each and females accepted $1.7 \pm 0.2$ spermatophores each in a lifetime. There was no significant correlation between longevity and spermatophores passed. Females laid $419.5 \pm 14.7$ eggs each of which $5.5 \%$ were sterile and retained 8 eggs at death. Oviposition began the 2 nd day of caging with males, and decreasing numbers of eggs were laid daily throughout the 
oviposition period. Females oviposited $48 \%$ of all eggs laid by the 4 th day of caging with males. Females laying more than the average percent af sterile eggs. tended to delay oviposition more than 1 day, to retain more than 10 eggs at death, and/or oviposit non-decreasing daily numbers of eggs during the oviposition period. There was no significant correlation among longevity, spermatophores accepted, total eggs laid, sterile eggs laid, and length of oviposition period. Correlation between number of eggs laid and number of fertile eggs was significant at the $1 \%$ level ( $r=8089)$. Correlation between the number of spermatophores accepted and the number of eggs retained at death was significant at the $5 \%$ level $(r=5006)$. Moths responded to sound of high and low frequencies at high amplitudes. Males were more responsive nocturnally than diurnally, but females showed little differential response. 


\section{LITERATURE CITED}

Agee, H. R. 1967. Response of acoustic sense cell of the bollworm and tobacco budworm to ultrasound. J. Econ. Entomol. 60: 366-369.

Alexander, R. D. 1957. Acoustical communication in arthropods. Annu. Rev. Entomol. 12: 495-526.

Arthur, B. W., and F. S. Arant. 1956. Control of soil insects atioching peanuts. J. Econ. Entomol. 49: 68-71.

As'n, C. R., and F. F. Bibby. 1957. Field test of soil treatmenis for prevention of stand destruction of grain sorghum by lesser cornstalk borer. Arizono Fertilizer, Inc. Crop Comments. 11: 2-4.

Bailey, L. H. 1949. Manual of cultivated plants. Macmillan Co., New York. $1116 \mathrm{p}$.

Bartlett, B. R., and C. H. Martin. 1945. A chemical method of freeing cocoons of Macroceriirus ancy!ivorus from iuber moth cocoons. J. Econ. Entomol. 38: 120.

Barth, R. 1937. Herkunft, Wirkung und Eigenschaften des weiblichien Sexualduit:stoffes einiger Pyraliden. Zool. Jahrb., Abt. Zool. Physiol. Tiere. 58: 297-329.

Belton, P., and R. Kempster. 1962. A field test on the use of sound to repel the European corn bore:. Entomol. Exp. Appl. 5: 281-288.

Berger, R. S. 1963. Laboratory techniques for rearing He! iothis species on artificial medium. U.S. Dep. Agr., ARS 33-84. 4 p.

[Bissell, T. L.] 1945. Lesser cornstalk borer, p. 63-64. In Ga. Agr. Exp. Sta. 57th annual report for 1944-1945.

[Bissell, T. L.] 1946. Lesser cornstalk borer on cowpezs, p. 82-84. In Ga. Agr. Exp. Sia. 58th: annuol report for 1945-1946.

Bissell, T. L., and M. Dupree. 1947. Vegetable insect pests. Georgia Agr. Exp. Sta. Bu!l. 254: 7-8. 
Bcurgogne, J. 1951. Ordre des Lépidoptères, p. 174-448. In Traite de Zoologie, vol. 10. Nasson et Cie, Paris.

Brindley, T. A. 1930. The growth and development of Ephestia kuehniella Zeller (Lepidoptera) and Tribolium confusum Duval (Coleoptera) uncer controlled conditions of temperature and relative humidity. Ann. Entomol. Soc. Amer. 23: 741-757.

Callahan, P. S. 1958a. Behavior of the imago of the corn earworm, Heliothis zea (Eoddie), with special reference to emergence and reproduction. Ann. Entomol. Soc. Amer. 51: 271-283.

Callahan, P. S. 1958b. Serial morphology as a technique for determination of reproductive patterns in the corn earworm, Heliothis zea (Boddie). Ann. Entornol. Soc. Amer. 51: 413-428.

Callohan, P. S., and T. Cascio. 1963. Histology of the reproductive tracts and iransmission of sperm in the corn earworm, Heliothis zea. Ann. Entomol. Soc. Amer. 56: 535-556.

Callahan, P. S., and J. B. Chopin. 1960. Morphology of the reproductive systems and mating in two representative members of the family Noctuidoe, Pseudaletia unipuncta and Feriodroma margaritosa, with comparison to Heliothis zea. Ann. Entomol. Soc. Amer. 53: 763-782.

Caivo, J. R. 1966. The lesser cornstalk borer Elasmopalpus lignosellus (Zeller) and its control. Unpublished Ph. D. Dissertation, Univ. of Fla. 70 .

Chittenden, F. H. 1900. Some irisects injuricus to garden crops. U.S. Dep. Agr., Div. Entomol. Bull. 23 n.s. 92 p.

Chittenden, F. H. 1903a. Some insects recently injurious to truck crops, p. 113120. In U.S. Dep. Agr., Div. Entornol. Bull. 40.

Chittenden, F. H. 1903b. The principal injurious insects in 1902, p. 726-733. In U.S. Dep. Agr. Yearbook for 1902.

Cholodkovsky, N. 1884. Über die Hoden der Lepidopteren. Zool. Anz. 7: 564-568.

Cline, L. D. 19ó7. Mating and reproduction of the granulate cutworm moth, Feltia subterranea (Fubricius). Unpublished Masters Thesis, Univ. of Fla. 49 p.

Cowart, F. F., and A. H. Dempsey. 1949. Pitriento production in Georgia. Ga. Agr. Exp. Sta. Bull. 259: 17.

Cunningham, W. H., Jr., D. R. King, and 3. C. Longley. 1959. Insecticidal control of the lesser cornstalk borer on peanuts. J. Econ. Entomol. 52: 329-330. 
Dekle, G. W. 1965. A lepidopterous larva on peach, p. 34-36. In Florida Dep. Agr., Div. Plant Industry, 25th Biennial Rpt.

Dempsey, A. H., and B. B. Brantley. 1953. Fimento production in Georgia. Ga. Agr. Exp. Sta. Bull. 227. 27 p.

Dethier, V. G. 1953. Chemoreception, p. 544-576. In Insect Physiology. K. D. Roeder ed. , John Wiley and Sons, New York.

Dickens, G. R. 1936. The scent glonds of certain Phycitidae (Lepidoptera). Trans。 Entomol. Soc. London. 1936: 331-362.

Dupree, M. 1964. Insecticidal and cultural control of the lesser cornstalk borer. Go. Agri. Exp. Sta. Mimeo. Ser. N. S. 197. 21 p.

Dupree, M. 1965. Observations on the life history of the lesser cornstalk borer. J. Econ. Entomol. 58: 1156-1157.

Dustan, G. G. 1964. Mating behavior of the oriental fruit moth, Grapholitha molesta (Busck) (Lepidoptera: Olethreutidae). Can. Entomol. 96: 1087-1093.

Eggers, F. 1919. Das thoracale bitympanale Organ einer Grouppe der Lepidoptera Heterocera. Zool. Jahrb., Anat. (Jena). 41: 273-376.

Eggers, F. 1925. Versuche über das Gehör der Noctuiden. Z. vergl. Physiol. 2: $297-314$.

Eggers, F. 1928. Die stiffführenden Sinnesorgane. Zool. Bausteine. 2: 1-351.

Eidmann, H. 1931. Morphologische und physiologische Untersuchungen am weiblichen Genitalapparat der Lepidopteren. II. Physiol. Teil. Z. angew. Entomol. 18: 57-112.

Fernold, M. L. 1950. Gray's manual of botany, 8th Edition. American Book Co., New York. 1632 p.

Forbes, S. A. 1905. A monograph of insect injuries to indian corn. III. State Entomol. 23rd Rpt. 273 p.

Götz, B. 1951. Die Sexualduftstoffe an Lepidopteren. Experientia. 7: 406-418.

Griffin, D. R. 1953. Bat sounds under naturol conditions with evidence for echolocation of insect prey. J. Exp. Zool. 123: 435-466.

Griffin, D. R., and A. Novick. 1955. Acoustic orientation of neotropical bats. J. Exper。Zool. 130: 251-299. 
Harding, J. A. 1960. Control of the lesser cornstalk borer attacking peanuts. J. Econ. Enteniol. 53: 664-6ú7.

Haskell, P. T. 1961. Insect sounds. Quadrangle Books, Inc., Chicago. 189 p.

Heinrich, C. 1956. American moths of the subfamily Phycitinae. U.S. Nat. Mus. Bull. 207. 581 p.

Henneberry, T. J., and A. N. Kishaba. 1967. Mating and oviposition of the cabbage looper in the laboratory. J. Econ. Entomol. 60: 692-696.

Hill, A. F. 1937. The nomenclature of the cultivated sorghums. Harvard Bot. Leafl. 4: 173-180.

Hitchcock, A. S. 1951. Manual of the grasses of the United States. Revised Edition. U.S. Dep. Agr. Misc. Publ. 200. 1051 p.

Howard, L. O. 1900. The principal injurious insects of the year 1899, p. 745748. In U.S. Dep. Agr. Yearbook for 1899.

Hughes, I. W. 1967. Reproductive behavior of the potato tuberworm, Phthorimaea operculella (Zeller), (Lepidoptera: Gelechiidas) and the effect of the chemosterilant metepa. Unpublished Ph. D. Dissertation, Univ. of Fla. 95 .

Isely, D., and F. E. Miner. 1944. The lesser cornstalk borer, a pest of fall beans. J. Kansas Entomol. Soc. 17: 51-57.

Jacobson, M. 1965. Insect sex attractants. Interscience Publishers, New York. $154 \mathrm{p}$.

Kelsheimer, E. G. 1955. The lesser cornstalk borer. Fla. Grower and Rancher. 63: 20,36 .

Kennel, J., and F. Eggers. 1933. Die abdominalen Tympanalorgane der Lepidopteren. Zool. Jahrb., Anat. (Jena). 57: 1-104.

King, D. R., J. A. Harding, and B. C. Langley. 1961. Peanut insects in Texas. Tex. Agr. Exp. Sta. MP-550. 14 p.

Kiriakoff, S. G. 1963. The Tympanic structures of the Lepidoptera and the taxoriony of the order. J. Lepidopterists' Soc. 17: 1-6.

Leuck, D. B. 1966. Biology of the lesser cornstalk borer in South Georgia. J. Econ, Entomol. 59: 797-801.

Luginbill, P., and G. G. Ainslie. 1917. The lesser corn stalk-borer. U.S. Dep. Agr. Bull. 539: 27 p. 
Lyle, C. 1927. The lesser cornstalk borer. State Plant Board of Mississippi, Quart. Bull. 7:2-3.

Musgrave, A. J. 1937. Histology of the male and fernale reproductive organs of Ephestia kuhniella. Proc. Zool. Soc, London. 1937: 337-364.

Norris, M. J. 1932. Contributions towards the study of insect fertility. I. The structure and operation of the reproductive organs of the genera Ephestia and Plodia (Lepidoptera, Phycitidae). Proc. Zool. Soc. London. 1932:595-611.

Norris, M. J. 1933. Contributions towards the study of insect fertility. II. Experiments on the factors influencing fertility in Ephestia kühniella $Z$. (Lepidoptera, Phycitidae). Proc. Zool. Soc. London. 1933: 903-934.

Novick, A. 1965. Echolocation of flying insects by the bat, Chilonycteris psilotis. Biol. Bull. 128: 297-314.

Ouye, M. T., H. M. Graham, C. A. Richmond, and D. F. Martin. 1964. Mating studies of the pink bollworm. J. Econ. Entomol. 57: 222-225.

Ouye, M. T., R. S. Garcia, H. M. Graham, and D. F. Martin. 19\$5. Mating studies on the pink bollworm, Pectinophora gossypiella (Lepidoptera: Gelechiidae), based on presence of spermatophores. Ann. Entomol. Soc. Amer. 58: 880-832.

Payne, T. L., and H. H. Shorey. 1968. Pulsed ultrasonic sound for control of oviposition by the cabbage looper moth. J. Econ. Entomol. 61:3-7.

Petersen, W. 1907. Über die Spermatophoren der Schmetterlinge. Z. wiss. Zool。 88: $117-130$.

Reynolds, H. T., L. D. Anderson, and L. A. Andres. 1959. Cultural and chemical control of the lesser cornstalk borer in southern Caiifornia. J. Econ. Entomol . 52: $63-60$.

Richards, O. W., and W. S. Thomson. 1932. A contribution to the study of the genera Ephestia, gn. (including Strymax, Dyar), and Plodia, gn. (Lepidoptera Phycitidae), with notes on parasites of the larvae. Trans. Entomol. Soc. London. 80: $169-250$.

Riley, C. V. 1882a. New insects injurious to agriculture, p. 272-273. In Proc. Amer. Asso. Adv. Sci. 30th meeting.

Riley, C. V. 1882b. New insects injurious to agriculture. Amer. Natur. 16: 152-153.

Roeder, K. D. 1962. The behavior of free-flying moths in the presence of artificial ultrasonic pulses. Anim. Behav. 10:300-304. 
. 1964. Aspects of the noctuid tympanic organ having significance in the avoidance of bats. J. Insect Physiol. 10: 529-546.

- 1966. Interneurons of the thoracic nerve cord activated by tympanic nerve fibers in noctuid moths. J. Insect Physiol. 12: 1227-1244.

Roeder, K. D., and A. E. Treat. 1957. Ultrasonic reception by the tympanic organ of noctuid moths. J. Exp. Zool. 134: 127-157.

- 1960. The acoustic detection of bats by moths. Proc. Intern. Congr. Entornol., 11th. 3: 8-11.

- 196la. The detection and evasion of bats by moths. Amer. Sci. 49: 135-149.

- 1961b. The reception of bat cries by the tympanic orgar, of noctuid moths, p. 545-560. In Sensory communication. W. A. Rosenblith, [ed.] John Wiley and Sons, Inc., New York.

Sanchez, L. O. 1960. The biology and control of the lesser cornstalk borer, Elasmopalpus lignosellus Zeller. Unpublished Ph. D. Dissertation, Texas

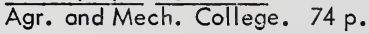

Schneider, D. 1964. Insect antennae. Annu. Rev. Entomol. 9: 103-122.

Schwink, I. 1953. Über den Sexualduftstoff der Pyraliden. Z. vergl. Physiol. 35: $167-174$.

Shorey, H. H. 1963. The biology of Trichoplusia ni (Lepidoptera: Noctuidae). 11. Factors affecting adult fecundity and longevity. Ann. Entomol. Soc. Amer. 56: 476-480.

- 1964. Sex pheromones of noctuid moths. I1. Mating behavior of Trichoplusia ni (Lepidoptera: Noctuidae) with special reference to the role of the sex pheromone. Ann. Entomol. Soc. Amer. 57: 371-377.

Shorey, H. H., L. A. Andres, and R. L. Hale, Jr. 1962. The biology of Trichoplusia ni (Lepidoptera: Noctuidae). 1. Life history and behavior Anr. Entomol. Soc. Amer. 55: 591-597.

Snow, J. W., and T. C. Carlysle. 1967. A characteristic indicating the mating status of male fall armyworm moths. Ann. Entomol. Soc. Amer. 60: 1071-1074.

Stahl, C. F. 1930. The lesser cornstalk borer (Elasmopalpus lignosellus Zell.) attacking strawberry plants. J. Econ. Eritomol. 23: 166.

Stitz, H. 1901. Der Genitalapparat der Mikrolepidopteren. II. Der weibliche Genitalapparat. Zool. Jahrb. Abt. Anat. 15: 385-434. 
Stone, K. J. 1968. Reproductive biology of the lesser cornstalk borer. I. Rearing technique. J. Econ. Entomol. In Press.

Treat, A. E. 1955. The response to sound in certain Lepidoptera. Ann. Entomol. Soc. Amer. 48: 272-284.

Treat, A. E. 1962. Comparative moth captures by an ultrasonic and a silent light trap. Ann. Entomol. Soc. Amer. 55: 716-720.

U.S. Department of Agriculture. 1952-1968. Coop. Econ. Insect Rpt.

Vorhies, C. T., and L. P. Wehrle. 1946. Pest problems of the small garden。 Ariz. Agr. Exp. Sta. Bull. 203: 33-34.

Walton, R. R., R. S. Matlock, and J. P. Boyd. 1964. Effect of the lesser cornstalk borer on peanuts in Oklahama. Okla. Agr. Exp. Sta. Processed Ser. p-474. $10 p$.

Webster, F. M. 1906. The principal injurious insects of 1905, p. 628-636. In U.S. Dep. Agr. Yearbook for 1905.

Williams, J. L. 1938. The mating of Ephestia kuehniella Zeller and its results. Entomol. News 49: 104-107, 121-126.

Williams, J. L. 1941. The relations of the spermatophore to the female reproductive ducts in Lepidoptera. Entomol. News 42: 60-65.

Wilson, J. W., and E. G. Kelsheimer. 1955. Insects and their control. Fla. Agr. Exp. Sta. Bull. 557. 28 p. 


\section{BIOGRAPHICAL SKETCH}

Kari Johnson Stone was born in Petoskey, Michigan, on 7 February 1935. He received his primary education at Central Grade School and his secondary educction at Petoskey High School, graduating in June 1953. He entered the University of Michigan in the fall of 1953, and received the degree of Bachelor of Science in June 1957.

He was admitted to the Graduate School of the University of Michigan in September 1957, and received the degree of Masters of Science in Biology in June 1959.

He was appointed to the position of Scientific Technician with the Arctic Research Laboratory, operated by the University of Alaska under contract with the Office of Naval Research in September 1959, and held the position until he was appointed Administrative Assistant to the Director, Arctic Research Laboratory, in August 1961.

He was admitted to the Graduate School of the University of Florida in September 1962. He was appointed to the position of Laboratory Technician with the Florióa Deportment of Agriculture, Division of Plant Industry in July 1963 and held the position until June 19ó5. He v/as appointed to the position of Research Associate with the University of Florida, Department of Entomology, in July 1965. 
Karl J. Stone is married to the former Margaret Ann Brand, and is the father of one child. He a member of the American Museum of New York, Society of Systematic Zoology, Entomological Society of America, and the Florida Entomological Society. 
This dissertation was prepared under the direction of the chairman of the candidate's supervisory committee and has been approved by all members of that committee. It was submitted to the Dean of the College of Agriculture and to the Graduate Council, and was approved as partial fulfillment of the requiremints for the degree of Doctor of Philosophy.

December, 1968

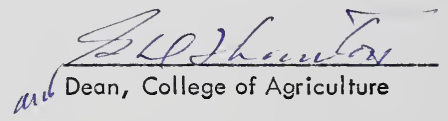

Dean, Graduate School

Supervisory Committee:
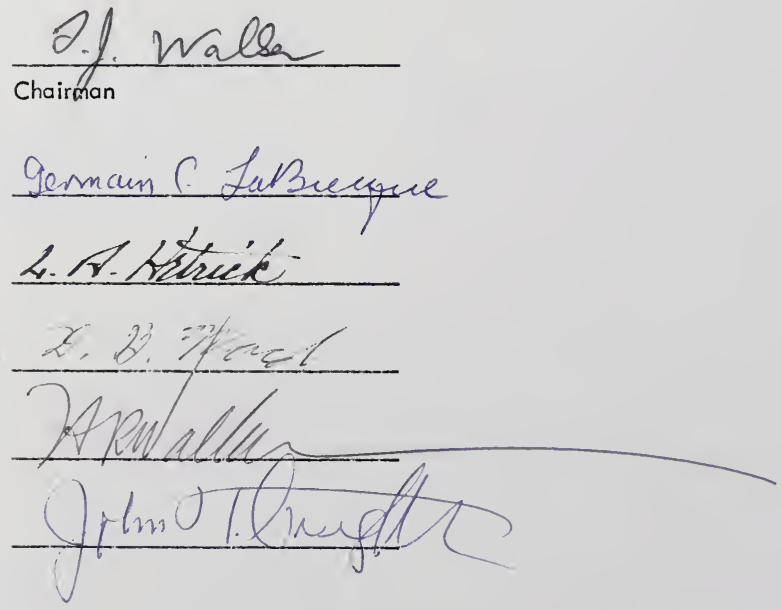
105

6242 